\title{
Driven from Work: Graduated Driver License Programs and Teen Labor Market Outcomes
}

\author{
Laura M. Argys, Thomas A. Mroz, and M. Melinda Pitts
}

\author{
Working Paper 2019-16 \\ July 2019
}

\begin{abstract}
In response to a high incidence of motor vehicle accidents among teens, states have adopted policies that broadly mandate restrictions on novice teen drivers, including more prelicensure education and supervised driving as well as postlicensure curfews and restrictions on the number of passengers. By making it costlier to obtain a driver's license and reducing the benefits of a license by limiting driving hours and restricting passengers, graduated driver licensing (GDL) may also alter the cost of activities that are complementary to driving. This research explores the unintended consequences GDL laws may have on the labor/leisure tradeoff of teens, as it alters the return to market work and the benefit of leisure. The results suggest that approximately half of the decline in teen labor force participation since 1995 can be attributed to the restrictions associated with graduated driver licenses.
\end{abstract}

JEL classification: J22, I18, H7

Key words: graduated driver licensing, teen labor force participation, driving restriction

https://doi.org/10.29338/wp2019-16

The authors thank Amanda Kay Seals, Astha Sen, Christopher McPherson, and Biplab Datta for research assistance. The authors are grateful for suggestions from seminar participants at the Southern Economic Association meetings, San Diego State University, Clemson University, and the Federal Reserve Bank of Atlanta. The views expressed here are those of the authors and not necessarily those of the Federal Reserve Bank of Atlanta or the Federal Reserve System. Any remaining errors are the authors' responsibility.

Please address questions regarding content to Laura M. Argys, Department of Economics, CB 181, University of Colorado Denver, P.0. Box 173364, Denver, C0 80217-3364, laura.argys@ucdenver.edu; Thomas A. Mroz, Georgia State University, Department of Economics, P.0. Box 3992, Atlanta, GA 30302-3992, tmroz@gsu.edu; or M. Melinda Pitts, Federal Reserve Bank of Atlanta, Research Department, 1000 Peachtree Street NE, Atlanta, GA 30309-4470, 404-498-7009, melinda.pitts@atl.frb.org.

Federal Reserve Bank of Atlanta working papers, including revised versions, are available on the Atlanta Fed's website at www.frbatlanta.org. Click "Publications" and then "Working Papers." To receive e-mail notifications about new papers, use frbatlanta.org/forms/subscribe. 


\section{Introduction}

In response to a high incidence of motor vehicle accidents among teens, states have adopted policies that broadly mandate restrictions on novice teen drivers. By 2012, all states had adopted graduated driver licensing policies that require additional pre-license driving experience and impose restrictions on teen driving in the initial post-licensing phase by either restricting driving at night or limiting the number of passengers, or both.

These programs, known as Graduated Driver License programs (GDLs), were designed to improve safety, and by many measures they were successful on this front. Research has found consistent and sizable reductions in accidents involving teen drivers (Grabowski and Morrisey, 2001; Dee, 2001; Eisenberg, 2003; Dee, Grabowski and Morrisey, 2005). These findings are consistent both with the notion that GDLs may reduce teen driving by delaying teen licensing and that they improve driving skills and performance among young teens who do obtain their licenses (Masten, Foss and Marshall, 2011). The adoption of GDLs is credited with reducing fatal accidents among teen drivers between the ages of 15 and 17 by as much as $5.6 \%$, with no conclusive evidence that the restrictions simply delayed adverse driving outcomes until the unrestricted driving phase (Dee, Grabowski and Morrisey, 2005).

In addition to improving safety on the road, there is, however, the potential that GDLs have unintended consequences. Sivak and Schoettle (2011) find that the share of 16-18 year olds with a license has fallen more than 20 percentage points during the time period of GDLs and that, combined with restrictions to independent driving during teen years could alter a number of other behaviors. ${ }^{1}$ By making it costlier to obtain a driver's license and reducing the benefits by

\footnotetext{
${ }^{1}$ Sivak and Schoettle (2011) find that the percentage of young drivers was inversely related to the availability of the internet. For this to be a concerning factor in this analysis, the introduction of the internet would have to be causal with respect to the introduction of GDLs, which is not the case. A report from the AAA Foundation found that almost $25 \%$ of unlicensed teens cite GDLs as a factor, with not having a car as the largest factor.
} 
limiting driving hours and restricting passengers, GDLs may also alter the cost of activities that are complementary to driving.

In particular, GDLs may alter the labor-leisure trade-off of teens. The impact of GDLs on teen labor force participation depends on the effect these restrictions have on the relative costs of teen work and leisure activities. Although both work and leisure are complementary to driving, if teens rely heavily on driving as the means of flexible transportation to and from work, GDLs may serve as a deterrent to work by making it costlier to obtain a driver license, thus potentially delaying licensure, and by limiting the driving hours and ability to carpool. In this paper we explore the possibility that these GDL restrictions, which were ushered in by concerns of safety, may also alter the work behavior of teens.

There are a sizable number of studies evaluating the benefits of work for students in high school, which is the group subjected to GDLs. In general, the research has focused on the shortterm impact of work on academic achievement and the longer run labor market outcomes. Studies suggest that moderate hours of work during high school do not interfere with, and in fact may enhance, academic performance. Oettenger (1999) finds that moderate work during high school is associated with increases in grades. Working more than twenty hours per week, however, reduces academic performance and, particularly among minority students, has substantial impacts that noticeably lower grade point average and class ranking. The evidence regarding the impact of student work on later labor market experience is fairly consistent. In particular, early studies suggest that work during high school translates into higher wages in early adulthood (Meyer and Wise, 1982); they estimate the return to high school work to be nearly 3\% higher wages for each year worked in high school. Later work has confirmed similar effects on wages (Ruhm, 1997) and these patterns appear to persist nearly 10 years after high 
school graduation (Carr, Wright and Brody, 2006). There is, however, some concern that the link between high school work and later labor market outcomes may be driven by sample selection (Hotz et al., 2002).

Exploiting variation in the adoption of GDLs and their provisions across states and over time, this analysis examines changes in labor force participation and work hours among teens between the ages of 15 and 18 . With this focus on labor-market behavior, we extend the analysis of standard features of GDLs to incorporate work exemptions designed to relax driving restrictions for employed teens. The findings suggest that GDLs significantly lower teen LFP, from both a statistical and an economic perspective. Work exemptions offset a small portion of the decline, with the impact of work exemptions being larger for females than for males.

\section{Background}

\section{Graduated Driver License Restrictions}

Teen drivers face automobile fatality rates three to four times that of middle-aged drivers (Morrisey, Grabowski, Dee and Campbell, 2006), a fact that has not gone unnoticed by policymakers. Teen fatalities may result from a lack of experience among young drivers, and the consequences of inexperience may be especially salient for nighttime driving, which presents increased risks due to reduced visibility and the presence of impaired drivers. However rather than simply inexperience, it may also be judgment and lack of caution that account for the disproportionately high rates of driving accidents involving teenagers. Teen drivers may also be more easily distracted by companions, music, or cell phones. 
In response to the high rates of serious accidents involving teen drivers, states raised the minimum driving age and introduced Graduated Driver Licenses (GDLs). ${ }^{2}$ Designed to improve driver safety and skill, GDLs place restrictions on young and inexperienced drivers by requiring additional supervised driving practice and limiting driving in difficult situations. Most GDL programs define three distinct licensing phases, the first of which is a permit-based instructional period (Insurance Institute for Highway Safety, IIHS, 2008). This phase typically requires that the driver pass a written examination and begin a supervised driving period. The second licensing phase, and the one that is the primary focus of this research, is a restricted-license driving period that begins when a driver completes her supervised permit period and is below the age of unrestricted driving. During this phase, GDL laws typically limit either the nighttime hours that a new driver can be on the road or the number of passengers that may accompany a teen driver or both.

The majority of passenger and driving-time restrictions were adopted by states during the 1990s and 2000s. By 1999, 24 states had implemented some form of a GDL, with the remaining states adopting their driving restrictions by 2012 (See Figure 1). The final phase of graduated licensing is the unrestricted phase. Generally, between the ages of 16 and 18, states with GDLs will allow teens to drive without hours or passenger restrictions. ${ }^{3}$ A large number of states allow exemptions for work, with some states requiring signed documentation from one's employer and other states being more lenient. The variation across states in the types of GDL restrictions, restriction age, the timing of implementation, and the enforceability of GDLs is utilized to

\footnotetext{
${ }^{2}$ Recently states have begun to impose penalties for texting or talking on cell phones while driving. In some states, such as Colorado, these laws are more restrictive for teen drivers than adult drivers.

${ }^{3}$ The one exception is Idaho, which lifts its passenger restriction at age $151 / 2$, and its hours restriction at age 16 .

Teens in Idaho are allowed to obtain their permit at 14 1/2 and their license at age 15.
} 
identify the effects of driver license restrictions on teenage labor force participation (See Table 1 for restriction information by state).

\section{Labor Force Participation by Teens}

During this same time period, there was a significant decline in teen labor force participation. In 1995, slightly less than half of teens were participating in the labor force. By the end of the analysis period, in 2015, that rate had fallen to 30\%, a nearly twenty-percentage point decline. While prime age LFP declined slightly during this time period (3\%), the decline was more than fifteen times larger for teens ages 16-17 and eight times larger for teens age 19-20 (see Figure 2). ${ }^{4}$ After almost two decades of decline, the participation rate of teens ceased its decline after 2011 and has leveled out at around 22\% for teens aged 16-17 and around 48 percent for teens aged 19-20, while the rate of decline for prime age LFP has continued its slightly negative trajectory.

There has been no definitive research to explain this decline. Aaronson et al. (2007) suggested that the increased returns to education has led to increases in school enrollment and lower probabilities of working while in school. Frisvold and Pitts (2018) found that College Merit Aid programs alter teen labor supply; however, the variation across states works to mitigate the effect on the national aggregates. Smith (2011) suggests that adults have crowded out teens in the low-skilled labor market, contributing between three to five percentage points of the decline in teen LFP, due to the increased occupational polarization driven by the declining cost of computerization, and automation. This is consistent with the findings of Aaronson et al. (2007), who find evidence that demand for teen labor is highly elastic. This suggests that the

\footnotetext{
${ }^{4}$ These calculations are based on the change in five year averages for LFP, comparing 1995-1999 to 2010-2014.
} 
impact of driver restrictions may not be limited to just the supply side if the GDLs also increase the cost of employing teens.

This goal of this research is to explore potential links between the observed decline in LFP for teens and the introduction of GDLs. As shown in Figure 1, the timing of both of these outcomes is suggestive of a relationship. The decline in teen LFP relative to prime age increases with the increased number of states enacting GDL legislation. Furthermore, the relative decline begins to flatten out in 2011, when the number of states with GDLs approaches 51.

\section{Data}

Detailed information on the GDL restrictions, discussed above, are obtained from the Insurance Institute for Highway Safety (IIHS 2015). The IIHS compiles and releases summary data that include the date of adoption of GDL restrictions and provides detailed state-by-state information on the minimum age at which a driver's license may be obtained, restrictions on the number (and age) of passengers that may accompany a teen driver, and the time any restricted driver curfew is in effect. This document contains information on the status of the state GDL system in 1995, and it details any changes in the plans that have occurred since then.

The timing of the adoption of GDL restrictions is concentrated in the 1990s and 2000s. There are, however, nine states that introduced restrictions before 1995; for seven of them the characteristics of the restrictions prior to 1995 are unknown other than that it existed. Thus our analysis begins in 1995. Table 1 provides a brief description of the GDL plans by state, including the year of introduction, the current minimum driving age, hour and passenger restrictions, and information on work exemptions. The restrictions on driving hours vary from states that require teen drivers to be off the road by sunset to those that only restrict teen driving after 1 a.m. 
Passenger restrictions vary from states that do not allow passengers at all to those that allow up to three passengers. Figure 1 summarizes the number of states with GDL restrictions by year. As of 1995 eight states already had restricted nighttime driving for new teen drivers. By 2015 all states, as well as the District of Columbia, have some sort of GDL restriction, with 50 states restricting driving hours and 47 with a passenger restriction.

Given that our interest in GDLs is related to the potential impact on the teen's labor/leisure trade off, it is also important to have information on whether a state allows for a work exemption from their GDL restriction. This information is not collected by IHHS and was, instead, obtained from each state's website on teen licensing. (See Appendix One for state DMV citations). However, historical information on the work exemption options were not available, so the current status is assumed to have been in place since the creation of the GDL.

In general, 37 states provide some sort of work exemption to their GDL restrictions. Twenty-nine of those states do not require any documentation of work schedule, while 7 states require the teen driver to have a note from their employer in the car. One state requires a note from parents to be in the car. If no note from an employer was required, a state is classified as having a minor work exemption. The seven states that require a note from the employer, California, Connecticut, Hawaii, New Jersey, New Mexico, Ohio, and Wyoming, are considered to have a strict work exemption.

There is considerable variation in the minimum driving age as well as the age at which restrictions are lifted. Minimum driving age ranges from as young as 14 years, six months in South Dakota up to age 17 in New Jersey, and driving restrictions in the form of passenger limits and driving hours are in effect at the time of becoming a licensed driver. States specify the ages when the restrictions remain in place. As shown in table 1 , restrictions are lifted as young as age 
15 years, six months and as old as 18 years of age. Thus, drivers in different states can begin driving at different ages and if there are restrictions, they are lifted at varying ages across states and time. Furthermore, within states, the restrictions can vary with age as older drivers can, for example, increase the number of passengers.

Data on labor force activity is obtained from the Current Population Survey (CPS), a nationally representative survey of 60,000 households each month. The survey provides demographic, education, and labor force information for the civilian non-institutional population. The survey collects information from households 8 times over the course of a 16-month horizon (4 months surveyed; 8 months off; 4 months surveyed).

The CPS includes detailed questions on labor market outcomes, including whether the individual is participating in the labor force (LFP), employed, and the actual hours of work in the previous week, if employed. Additional individual characteristics include age, race, and gender. Summary statistics are provided in Table 2a. The sample of 15-18 year olds has somewhat more males $(394,034)$ than females $(358,600)$. The average age of both genders are almost 17 years old. There are also similar racial distributions, with each gender composed of approximately 12\% non-Hispanic blacks, 15\% Hispanics, 67\% non-Hispanic whites, and 6\% others. The labor force participation rate is $38 \%$ for both genders, but males work 20.5 hours, conditional on hours $>0$, while females work slightly less at 17.9 hours.

We merge details of the state GDL programs with the CPS based on the reported state of residence. Unfortunately, age information in the CPS is limited to integer age, with no direct information on date of birth. Given that these laws can impact individuals aged one month apart very differently, the empirical model assigns each individual a probability distribution for their age at each survey date (and hence their date of birth) as described below. 


\section{Empirical Model}

We use monthly Current Population Survey (CPS) data from January 1995 through December 2014 to estimate the impact of GDL restrictions on labor market decisions for individuals with reported ages 15 to 18 that have information on labor force outcomes. We assume three different models can describe the relationship between the explanatory variables and the outcomes of interest. The models differentiate among classes of individual exposure to GDL restrictions. The first model describes the relationship for individuals who are currently subject to some type of GDL restrictions (class R). The second model applies to those who were formerly subject to some GDL restrictions but currently are not subject to any restrictions (class F). The third model applies to those driving-eligible individuals who were never subject to any GDL restrictions (class N). We use the individual's current state of residence to describe their exposure to GDL restrictions at all eligible driving ages, that is, we assume each individual has resided in the state that they reported at the time of the CPS interviews since they attained the minimum age to drive.

The CPS data do not contain information on the exact date of birth. Because only integer ages are reported, the respondent's exact age is not known and we cannot assess precisely their current or previous exposure to GDL restrictions. To overcome this limitation, we exploit the fact that, for many respondents, we have up to 8 months of observations in the CPS and this allows us to more narrowly bracket the birth month. We limit the analysis to individuals whose reported ages in all of their CPS interviews were consistent across all survey months (e.g., no one ages by more than one year in any 12-month span).

For example, suppose someone entered the CPS in February 2000 at age 16. We know that the person could have turned 16 at the end of February 1999, or at any month from March 
1999 through January 2000, or even at the beginning of February 2000. Suppose this individual then reports being age 17 at their next interview in March 2000. In that case, we know that she turned age 16 either at the end of February 1999 or at the beginning of March 1999. If, instead, the individual continues to report being age 16 in the March 2000 survey, then we know she could not have turned 16 in the end of February 1999 or at the beginning of March 1999. Her reported age at the second interview limits the range of possible dates when she could have turned age 16. We continue to look at the individual's age in each subsequent interview (April and May 2000 and February through May 2001) to further narrow the range of dates when she could have turned age 16 . Once we know the range of dates when she could have turned 16, we construct the range of dates when she was born. This bracketing of birthdates is important as some GDL restrictions change at six- and nine-month age benchmarks, as well as others at exact integer ages. Note that we use observed information across all the CPS surveys for each individual to help bracket the date of birth.

We merge these ranges of birth dates with the state-level monthly natality files from the Centers for Disease Control and Prevention. For each month we know the number of children who were born in each state. ${ }^{5}$ We then add up the number of births that took place in each month for each individual's range of possible birth months in their state of residence (assuming that half-months had half the number of births that took place in that month). We then assume that the probability the individual was born in each of those months equals the ratio of the number of births in that particular month to the total number of births that took place within her range of possible birth months. This allows us to assign a probability (often 1 or 0 ) to whether she was

\footnotetext{
${ }^{5}$ For these refined calculations of the possible ranges of birthdates, we assume the individual had been born in the state of residence observed in the CPS data.
} 
restricted by GDL laws, formerly restricted or never restricted at each month of her being observed in the CPS datasets. The weighted average of GDL exposure probabilities are shown in Table 2b. In general, the sample is nearly evenly divided among the three types of exposures.

Let an individual's current GDL status be denoted by R, F, and N, where R signifies that the individual currently faces GDL restrictions, F denotes that she currently is not restricted but formerly did face GDL restrictions, and N means that she never faced a GDL restriction. Let $p^{R}(i, t)$ be the probability individual i faced GDL restrictions at date $t$ calculated using the method just defined. It is a function of an information set in the CPS data that we denote by $\Omega(i)$. Similarly, $p^{F}(i, t)$ is the probability that the individual formerly faced GDL restrictions but currently (at time t) does not face GDL restrictions. The probability that the individual never faced GDL restrictions is given by $p^{N}(i, t)=1-p^{R}(i, t)-p^{F}(i, t)$. Let each of the three regression functions for each outcome $y(i, t)$ be given by

$$
E[y(i, t) \mid X(i, t), \text { status }]=\beta_{\text {status }}^{\prime} X(i, t), \quad \text { for status }=R, F, N
$$

where $X(i, t)$ is a column vector of explanatory variables that could vary with exposure to the GDL restrictions and status signifies which of the GDL exposure groups the observation actually belongs to at date t. Combining the three regression functions together yields

$$
\begin{gathered}
E[y(i, t) \mid X(i, t), \text { status }=s]= \\
{\left[\beta_{R}^{\prime} X(i, t)\right] 1(s=R)+\left[\beta_{F}^{\prime} X(i, t)\right] 1(s=F)+\left[\beta_{N}^{\prime} X(i, t)\right] 1(s=N)}
\end{gathered}
$$

In many cases, because precise age is not known, we do not know exactly which GDL regression model is appropriate. However, since we do know the probability for each model at 
date $t$, we can specify the regression model only conditional on the explanatory variables $X(i, t)$ and the information used to bracket the range of possible birth dates, $\Omega(\mathrm{i})$, as

$$
\begin{gathered}
E\{E[y(i, t) \mid X(i, t), \text { status }] \mid X(i, t), \Omega(\mathrm{i})\}= \\
E[y(i, t) \mid X(i, t), \Omega(\mathrm{i})]=\beta_{R}^{\prime}\left[X(i, t) p^{R}(i, t)\right]+\beta_{F}^{\prime}\left[X(i, t) p^{F}(i, t)\right]+\beta_{N}^{\prime}\left[X(i, t) p^{N}(i, t)\right]
\end{gathered}
$$

Given variations in the probabilities of being in each of the three GDL exposure groups across individuals and time periods, each of the $\beta_{r}$ parameter vectors are identified.

Each regression specification includes a quadratic in age (with all age terms accounting for the uncertainty of the birth date in a similar fashion to the derivation of the probabilities of the various GDL status indicators), race (non-Hispanic white, non-Hispanic black, Hispanic, other), and time-varying state-level measures related to the labor/leisure choice, including beer tax, cigarette price, gasoline price, state level median income, unemployment rate and state population, all in logarithmic form. We also include state-level and month-level fixed effects from January 1995 through December 2014, although it should be noted that here are no "never restricted" observations after 2012, as well as state-specific, linear time trends. Except for the state-specific time trends, there are separate coefficients for all variables in each of the three regression models.

To calculate the effects of the various GDL restrictions, we compare the regression functions of one GDL restricted group to one of the other two groups. Suppose the treatment group is the currently restricted group, group R, and the comparison group is the never restricted, group N. (Making comparisons between any other two groups follows the same approach). Let 
$E_{\text {state }}$ be the estimated impact of the GDL restrictions for a state. We define this impact for the currently restricted versus the never restricted as:

$$
E_{\text {state }}=\left(\beta_{R}-\beta_{N}\right)^{\prime} \tilde{X}_{\text {state }}
$$

Define $\tilde{X}_{\text {state }}$ as the weighted mean of the explanatory variable vector in the state, using the probability of being in the currently restricted group for each observation as the weight (i.e., we use the $p^{R}(i, t)^{\prime} s$ for those individuals residing in the state to construct the weighted average of the X's). ${ }^{6}$ With very early adoption of GDLs, two states never had unrestricted drivers during the sample time frame, and those states are deleted from the calculation of effects since the counterfactual of teens untreated by a GDL was never observed. ${ }^{7}$ We do include these two states in the estimation of the regression model.

This estimated impact of GDL restrictions for the state reflects the distribution of the characteristics of GDL restricted individuals. Note that this effect incorporates the possibility that time effects or time-varying state characteristics impact currently- and never-GDL-restricted individuals differentially, so it is a generalized difference-in-difference definition of the GDL impact in that state.

To fully understand the impact of GDLs on teen labor force behavior, we classify each state's GDL restrictions into one of three groups depending on whether or not the state permits exceptions to its GDL laws for "covered” youth commuting to or from work. States that allow no exemptions for work-related travel comprise the first group. The second group consists of states

\footnotetext{
${ }^{6}$ When comparing the formerly restricted to the never restricted, we instead use the distribution of the probabilities of being a formerly GDL restricted individual.

${ }^{7}$ Those two states are Louisiana and Pennsylvania have a known GDL start date of before 1995 . They were, however, used in the estimation of the regression coefficient but not in the calculation of effects since the counter factual of those untreated by GDL was never observed. Several other states, Idaho, Illinois, Maryland, Massachusetts, New York, and South Carolina, do not currently have a known start date and observations from those states are not included in this analysis.
} 
that allow exemptions but require a strict verification of work activities; the third group allows exemptions for youths driving to and from work but their work-verification policies are fairly $\operatorname{lax}$.

We report five types of effects that aggregate across the state-specific effects described above. The five effects are for: 1) all states with any type of GDL, 2) states with GDLs that had no work-related exemptions, 3) states that allowed for work-related GDL exemptions, 4) states with a strictly defined GDL work-related exemption, and 5) states with work-related exemptions that were less imposing. Each of these five effects corresponds to a weighted average of the state-specific GDL effects for those states falling into each of these categories, so these five effects often include many of the same GDL restricted states. The state-specific weights are defined as the sum of the probabilities of being currently covered within the state across all individuals and time periods. ${ }^{8}$ When we compare the 'formerly GDL-exposed' to the 'neverexposed', we use the state specific sum of the probabilities of being a formerly-exposed individual (the $p^{F}(i, t)$ 's) as the weights to construct average effects from the state-specific effects.

We estimate this model by OLS. Since we include monthly time dummies, state dummies, and state-specific linear trends, we cluster the standard errors within states at each month in time. ${ }^{9}$ The estimated effects are linear combinations of differences in coefficients between two of the three sets of regression coefficients, where the multipliers for the linear combinations depend on averages of the explanatory variables for the treated group as described

\footnotetext{
${ }^{8}$ This is equivalent to taking weighted averages of the explanatory variables across all observations in all states and time periods using the individual $p^{R}(i, t)$ 's as the weight.

${ }^{9}$ Clustering instead at the state level resulted in largely similar estimated standard errors in our main analysis.
} 
above. We use standard analytic formulae for linear combinations of estimated coefficients along with the estimated variance-covariance matrix to calculate standard errors of the effects.

\section{Results}

\section{Labor Force Participation}

As noted earlier, our empirical strategy provides a comparison of the predicted probabilities of participating in the labor force for a fixed population when exposed to graduated driver licensing (either currently or previously) versus the predicted probability of labor force participation with no such restrictions. More specifically, we calculate the predicted probability of labor force participation for a person who had been exposed to a GDL with a particular form of GDL work exemptions to the predicted labor force participation probability for an otherwise identical, counterfactual, individual who did not face a GDL restriction. Since we have detailed state effects in our estimation models that differ by the type of exposure to a GDL, we can only construct counterfactual, non-exposed individuals in the set of states that switched from no GDL restrictions to having GDL restrictions over the course of our sample period. The results of our initial model, reported separately by gender, are shown in Table 3.

The first two columns of Table 3 compare the predicted probability of labor force participation for the teens currently covered by GDL programs to those not who are never covered. Each row presents differences in predicted probabilities for one aspect of a GDL, beginning with simply comparing teens in states with any GDL to teens in states in years without a GDL. In general, the presence of a GDL reduces teen labor force participation for those covered by GDLs relative to those that are not, with the impact for males being slightly larger than for females. Specifically, LFP is 7.1 percentage points lower for males who are impacted 
by a GDL as compared to unaffected males; being affected by a GDL results in a decline in LFP for female teens of 5.4 percentage points.

Some states tried to mitigate the negative impact of GDLs on teen LFP by exempting teens from driving restrictions while travelling to work, and the presence and type of work exemptions impact teen LFP in the expected manner. As shown in the remaining rows of table 3, these exemptions diminish the effect of GDLS on teen LFP, but the effects differ notably by gender. For both males and females, the impact of GDLs with no work exemption on LPF is larger in magnitude than the impact in states that have a work exemption in place. The work exemption effect is much larger for female than males; i.e. young females seem relatively better motivated to respond to their state's GDL work exemptions. It is important to note that the configuration of states does change across evaluations of the various forms of exemptions to the GDL restrictions.

The strictness of the work exemption also matters, although for males, the magnitude of the difference between strict and weak work exemptions is small. Male teens affected by GDLs with strict work exemptions (i.e. those that require strict verification of work activity by requiring written confirmation of work from an employer) exhibit only slightly smaller reductions in LFP as compared with male teens in states with less 'costly' work exemptions that require no such documentation. Specifically, relative to teens facing no GDLs at all, the reduction in male LFP in states without exemptions is 7.5 percentage point; this impact falls to 7.2 percentage point with strict work exemptions, and to 6.8 for states with minor work exemptions.

The impact of work exemptions on female teen labor supply is much more pronounced. Females in states with GDLs without any work exemptions are 8.9 percentage points less likely 
to be in the labor force than females in states with no GDL restrictions. The presence of a work exemption results in a LFP that is only 4.6 percentage points less than unrestricted female teens. This suggests that the presence of a work exemption matters substantially for females. One possible factor is the work schedule for the industries preferred by females. According to the American Time Use Survey, the leisure and hospitality industry, which employs a greater share of employed teen females relative to the share of employed teen males, has more employees working during the hours of 9:00pm and 2:00am (in the period 2003-2007) than any other industry, at 15 percent. The industries where the share of employed teen males dominates the share of females, manufacturing as well as finance and business services, there are approximately nine and five percent, respectively, working during those hours. ${ }^{10}$

The last two columns of Table 3 compare teens formerly covered by a GDL to teens never covered by a GDL. As labor force participation appears to be diminished in the presence of driving restrictions, this analysis sheds some light onto how these teens will respond once the driving restrictions are lifted. It is possible that these teens have developed habits in driving and work behavior that will persist in the absence of restrictions or that the demand side of the labor market has diminished for teens. Comparing teen drivers who aged out of the restrictions in their states to counterfactual drivers of the same ages that have never faced GDL restrictions in the same states at those same points in time, the results in Table 3 provide evidence that reductions in LFP from GDLs persist beyond the restricted driving period. ${ }^{11}$ Although somewhat smaller than the initial effects, the reduction in LFP associated with being a formerly restricted driver is

\footnotetext{
${ }^{10}$ See https://www.bls.gov/tus/tables/a5_0913.htm for more detail on the industry work schedules. The years 20032007 were the earliest years available and have the advantage of being less influenced by both the presence of GDLs and the great recession.

${ }^{11}$ Delayed licensure may explain the persistence of these effects.
} 
still substantial. Restricting access to the labor force at younger ages has lasting effects in the immediate year(s) after the teens age out of the GDL program.

\section{Sensitivity Analysis}

While the results in Table 3 focus on the extensive margin, the analysis in Table 4 focuses on hours of work, conditional on hours being greater than zero. These results suggest that the limiting behavior of GDLs is on the extensive margin, as, especially for males, if a teen works in a state with a GDL (with or without a work exemption), hours of work are actually higher than for those that are not covered. It could be that, because of the increased cost of getting to work, once this cost is incurred, teens will work more hours. Alternatively, it could be the case that those choosing to work in the face of GDL restrictions are those who would have worked more hours even in the absence of GDL restrictions; those exiting (or choosing not to enter) the workforce because of the GDL might have lower work commitments.

Given that metropolitan areas, on average, have relatively better access to public transportation than non-metropolitan areas, the above analysis was repeated to see if the more rural population was driving the results. The results, shown in Table 5, suggest that this is not the case. The coefficients, for the most part, are relatively similar in magnitude to the overall results, with some weak evidence that young females are more affected by GDL restrictions in nonmetropolitan areas. The lower precision in the results for the non-metropolitan areas reflects the smaller sample size within the non-metro areas.

In Tables 6A and 6B, we explore the implications of the methodology used to assign an individual's age. The first two columns of each table use the preferred weighted (probabilistic) prediction of GDL status shown in Table 3, while in the last two columns everyone is assigned their integer age plus six months to determine "exact” exposure to the GDLs. In Table 6A, the 
comparison is between covered and never covered. In general, the coefficients are smaller than the preferred methodology for males, while the coefficients for females are slightly larger than with the preferred methodology. The results in table 6B, for the formerly GDL exposed versus the never exposed, follow a similar pattern. In general, the unweighted method typically yields less precision.

\section{Robustness}

There is concern that the implementation of GDL laws could be correlated with other factors in the state, such as changes in the value of home-time, changes in parenting style, and/or changing economic conditions that could impact teen labor force participation.. It is plausible that as parents have become more involved in their children's lives, (i.e. as 'helicopter parents'), that this could simultaneously influence the passage of the driver license laws and the likelihood of teen participation in the labor force, leading to biased estimates. However, the rise in involved parenting began to take place well before the introduction of the GDL laws studied here, as evidenced by the term "helicopter parent” being coined in 1990 by Cline and Fay (1990). The value of home-time has also changed with the introduction of on-line gaming and streaming. If teens reallocated their leisure toward home-based activities, driving restrictions would raise the price of work relative to leisure, strengthening the relationship between GDLs and labor force reduction. Such a relationship is unlikely to be driving the results in our analyses since most of the innovation in home entertainment took place during the latter part of the first decade of the 2000s, after most states had implemented GDLs. For example, Netflix began offering hybrid plans with streaming and DVD rentals in 2007, but streaming-only plans did not come about until 2011 (Littleton and Roettgers, 2018). Regardless, given the geographic and time 
dispersion of the introduction of the GDL laws, it seems unlikely that state specific changes in parenting styles or changes in the value of home time would impact labor force participation in such a way that would be related to the timing of the introduction of GDL laws.

To test whether changing economic conditions impacting employment could be a factor in the results, a placebo test was performed on 66-69 year olds, a group that would likely be as much, or more, vulnerable to changing economic conditions and are also much less likely to have a child in the driving age group than prime-age adults. To that end, the data was normalized such that 67-year olds were treated as 16-year olds and everyone was treated as if they were a teenager in high school. Then the same model that was used for the teenagers was estimated for the older sample. The results differ dramatically from those for teenagers, with only small, statistically insignificant impacts on LFP and hours. For females, the signs were reversed from the results for the teenagers, suggesting that GDLs increased employment for older females. These results might suggest that teenagers and older workers are substitutes. In summary, there were no statistically significant or large effects of the placebo law changes for this older population, reducing concern that unobservable changes in state labor markets correlated with GDL adoption might be driving our results.

\section{Conclusion}

The results of this research are summarized in Figures 2a- 2c. Limiting the analysis to states that had periods of time both with and without GDL restrictions, one can see that the overall LFP rate dropped from above $45 \%$ to below 30\% in 2012. The results of the analysis suggest that approximately half of this decline (8 percentage points) can be attributed to the restrictions associated with graduated driver licenses. It appears that the gap was exacerbated by 
the great recession, perhaps as firms has increased availability of older workers that did not face any driver restrictions, suggesting that the higher elasticity for teen employees found by Aaronson et at. (2007) plays a role here as well. Figures 2b and 2c separate out the impact by gender, but the results are similar for both groups.

The evidence is clear that GDLs reduce teen accidents and fatalities from moving vehicle accidents. ${ }^{12}$ However, these gains appear to come at the cost of less labor market exposure for teens. The presence of work exemptions in some states suggests that lawmakers at least considered this impact on the ability to work. These exemptions do mitigate the impact of GDL restrictions, although only slightly. In other words, states have traded increased safety for less work experience and income for teens. The evidence suggests that in 2014 alone, there were approximately 60 fewer fatal accidents nationwide ( 5 per month) because of the presence of GDLs. This is a lower bound on the impact of GDLs as there is no information on injuries from non-fatal accidents or the cost of car repairs for any incident. On the other hand, in December of 2014, these results suggest that there were almost 250,000 fewer teens in the labor force due to the presence of GDLs.${ }^{13}$ While this may be a reasonable trade off, given that teen work experience during high school is important for future outcomes, policymakers and schools may look to enhance work readiness and facilitate work experience to offset this decline associated with the restrictions for new drivers under GDLs.

\footnotetext{
12 There is also some suggestive evidence that there could also be a reduction in some forms of risky behavior (Deza, 2019; Argys, Pitts, Mroz, 2018).

${ }^{13}$ In 2014 there were 1,011 fatal accidents involving a teen driver. Given that GDLs have been found to reduce the probability of a fatal accident by 5.6 percentage points, this suggests that, in the absence of GDLs, there would have been almost 60 more fatal accidents in 2014, which is an amount similar to other years post GDL implementation. The same process was used to estimate the reduction of teens in the labor force due to GDLs. One note, as LFP is only available for 16-17 year olds and 18-19 year olds and not by individual age, the impact of 16-17 year olds was done using the effect of current and 18-19 year old reduction in the size of the labor force was calculated using former. In addition, the total effect was cut if half to reflect the absence of 19 year olds in this analysis.
} 


\section{Cited Work}

Aaronson, Daniel, Kyung-Hong Park, and Daniel Sullivan, 2006, “The decline in teen labor force participation,” Economic Perspectives, Federal Reserve Bank of Chicago, Vol. 30, No. 1, First Quarter, pp. 2-18.

Bertrand, M., E. Duflo, S. Mullainathan, (2004) "How much should we trust differences-indifferences estimates?” Quarterly Journal of Economics, 119(1): 249-75.

Carpenter, C. (2004). “How do zero tolerance drunk driving laws work?: Journal of Health Economics, 23(1):

Carpenter, C. (2006). “Did Ontario’s Zero Tolerance Policy and Graduated Driver Licensing Laws Reduce Youth Drunk Driving?” Journal of Policy Analysis and Management, 25(1): 18395.

Carr, RV, JD Wright \& CJ Brody. (2006). "Effects of high school work experience a decade later: evidence from the National Longitudinal Survey.” Sociology of Education, 69(1): 66-81.

Centers for Disease Control and Prevention (2009). "Announcement: National Teen Driver Safety Week.” Mortality and Morbidity Weekly Report, 58(40): 1125-1126. http://www.cdc.gov/mmwr/preview/mmwrhtml/mm5840a3.htm

Cline, Foster W. and Jim Fay (1990) "Parenting with Love and Logic: Teaching Children Responsibility” Navpress, Colorado Springs, Colorado.

Dee, T, D Grabowski \& M Morrisey (2005) Graduated driver licensing and teen traffic fatalities. Journal of Health Economics, 24(3): 571-589.

Eisenberg, D. (2003) "Evaluating the effectiveness of policies related to drunk driving. Journal of Policy Analyses and Management, 22(2): 249-274.

Foss, R., Feaganes, J, Rodgman, E. (2001) Initial effects of graduated driver licensing on 16year-old driver crashes in North Carolina. JAMA, 286(13): 1588-1592.

Frisvold, David E. and M. Melinda Pitts. "State Merit Aid Programs and Youth Labor Market Attachment”. NBER Working Paper No. 24662 June 2018.

Governor's State Highway Driving Association. (2016) Graduated Driver Licensing (GDL) Laws. http://www.ghsa.org/html/stateinfo/laws/license_laws.html. May, 2016.

Grabowski, D \& M Morrisey, (2001). “The effects of state regulations on motor vehicle fatalities for younger and older drivers.” Milbank Quarterly, 79(4): 517-545.

Hollis, S and F Campbbell (1999). "What is meant by Intention to Treat Analysis? Survey of Published Randomised Controlled Trials.” BMJ, 1999: 319-670. 
Hotz, VJ, LC Xu, M Tienda \& A Ahituv, (2002). "Are there returns to the wages of young men from working while in school?” The Review of Economics and Statistics, 84(2): 221-36.

Insurance Institute for Highway Safety. (2011). "Effective dates of graduated driver licensing." http://www.iihs.org/laws/pdf/gdl_effective_dates.pdf (last accessed 4/15/2011).

Insurance Institute for Highway Safety. (2008) “Licensing systems for young drivers.” http://www.iihs.org/laws/graduatedLicenseIntro.aspx (last accessed 1/10/2011).

Insurance Institute for Highway Safety. (2011). “Safety belt use laws.” http://www.iihs.org/laws/SafetyBeltUse.aspx (last accessed 2/25/2011).

Littleton, C and J Roettgers. (2018). “Ted Sarandos on how Netflix predicted the future of TV.” Variety, August 21. https://variety.com/2018/digital/news/netflix-streaming-dvds-originalprogramming-1202910483/

Masten, S, R. Foss, and S Marshall. (2011).“Graduated Driver Licensing and Fatal Crashes Involving 16- to-19- Year-Old Drivers.” Journal of the American Medical Association, Vol 306 10.): 1098-1103.

Meyer, RH and DA Wise. (1982). "High School Preparation and Early Labor Market Experience.” in The Youth Labor Market Problem: Its Nature, Causes, and Consequences R.B. Freeman and D.A. Wise, eds. University of Chicago Press: Chicago, IL.

Morrissey, M, D Grabowski, T Dee \& C Campbell. (2006) “The strength of graduated driver license programs and fatalities among teen drivers and passengers.” Accident Analysis and Prevention, 38(2006): 135-141.

National Survey on Drug Use and Health (2004), "Graduated Driver Licensing and Drinking among Young Drivers.” April 30, 2004. http://www.oas.samhsa.gov/2k4/licenses/licenses.htm

National Highway Traffic Safety Administration (NHTSA) "Teen Drivers - Graduated Driver Licensing. http://www.nhtsa.gov/Driving+Safety/Teen+Drivers/Teen+Drivers+-

+Graduated+Driver+Licensing

National Highway Traffic Safety Administration (NHTSA), (2019) Fatality Analysis Reporting System (FARS) Encyclopedia Query Tool. https://wwwfars.nhtsa.dot.gov/QueryTool/QuerySection/SelectReportFormat.aspx . Last accessed on March 22, 2019.

O’Donohue, T. and M. Rabin. (2001). "Risky behavior among youths: Some issues from behavioral economics." Chapter 1 in Risky Behavior among Youths: An Economic Approach. J. Gruber, ed. Chicago: University of Chicago Press.

Oettinger, GS. (1999). "Does high school employment affect high school academic performance?” Industrial and Labor Relations Review, 55(1): 136-151, 
Ruhm, C. (1997). “Is high school employment consumption or investment?” Journal of Labor Economics, 14(4): 735-776.

Shope, J, Molnar, L, Elliott, M, \& Waller, P (2001) Graduated driver licensing in Michigan: Early impact on motor vehicle crashes among 16-year-old drivers. JAMA, 286(13): 1593-1598.

Simons-Morton, B., M Ouimet. (2006) "Parent involvement in novice teen driving: a review of the literature.” Injury Prevention, 12(1): i30-i37.

Sivak M, Schoettle B.(2011) Recent changes in the age composition of US drivers: implications for the extent, safety, and environmental consequences of personal transportation. Traffic Inj Prev. 12:588-592.

Sivak M Schoettle B. (2012) Update: Percentage of Young Persons With a Driver's License Continues to Drop, Traffic Injury Prevention, 13:4, 341-341, DOI:

10.1080/15389588.2012.696755

Stanton, B., X. Li, J. Galbraith, G. Cornick, S. Feigelman, L. Kaljee, \& Y. Zhou. (1999). "Parental underestimates of adolescent risk behavior: a randomized, controlled trial of a parental monitoring intervention. Journal of Adolescent Health, 26(1): 18-26.

Ulmer, R, Preusser, D, Williams, A, Ferguson, S, \& Farmer, C. (2000) Effect of Florida's graduated licensing program on the crash rate of teenage drivers. Accident Analysis and Prevention, 32(4): 527-532. 
Figure 1

Number of State with Graduated Driver's License Programs and the Labor Force Participation of Teens relative to prime age work force (25-54)

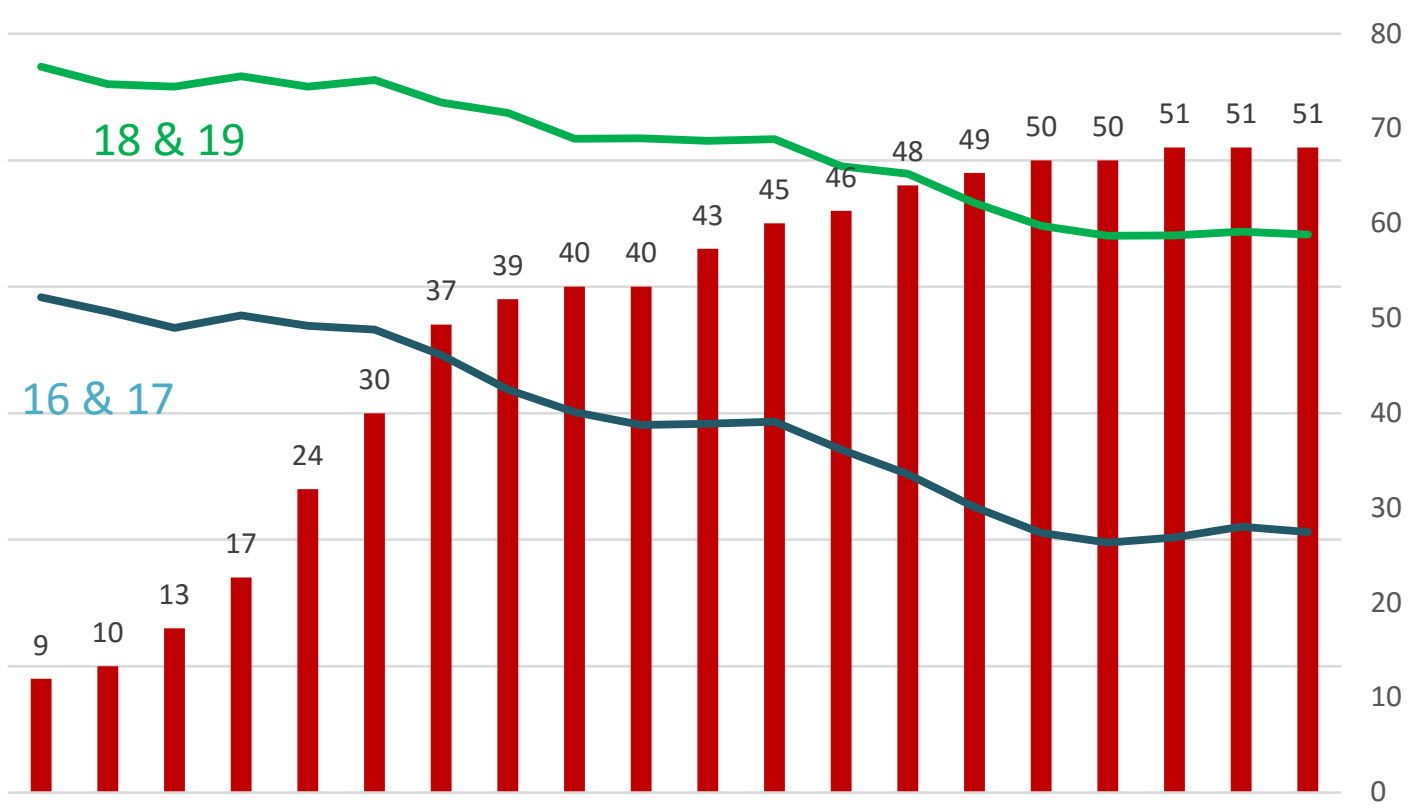

19951996199719981999200020012002200320042005200620072008200920102011201220132014 
Figure $2 \mathrm{a}$

all: Predictions of Driving Eligible Youth LFPR

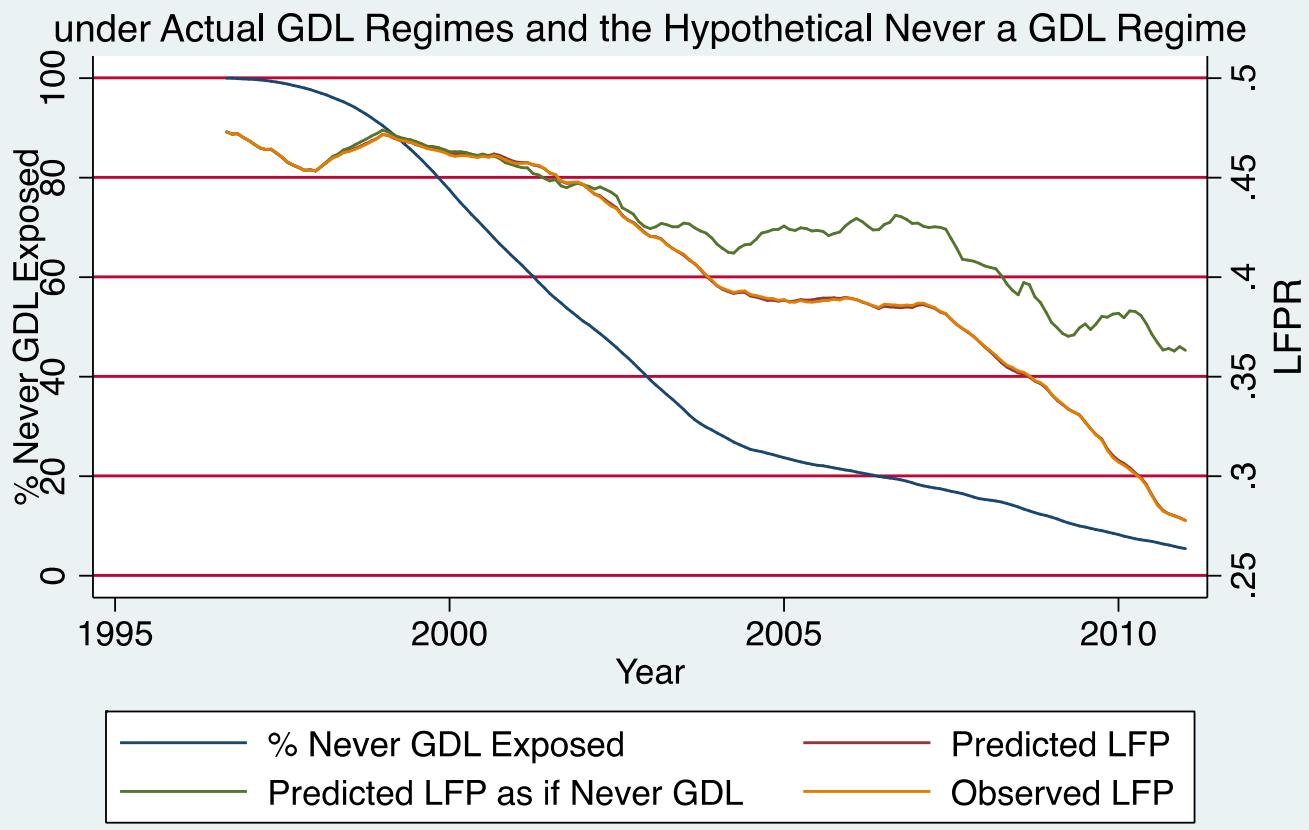

Only states observed with and without GDL restrictions; prior 12 month moving averages

Figure $2 b$

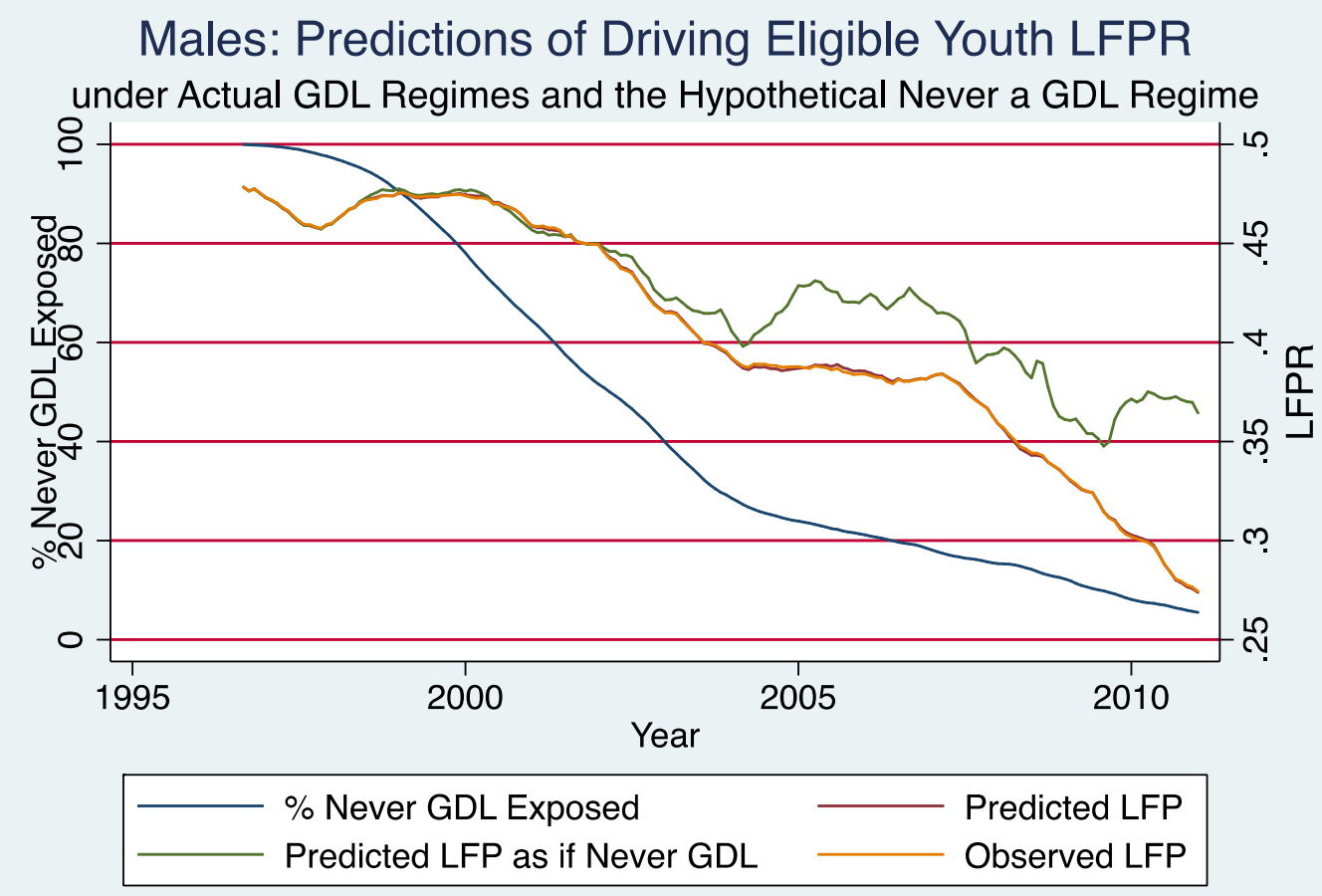

Only states observed with and without GDL restrictions; prior 12 month moving averages 
Figure 2c

Females: Predictions of Driving Eligible Youth LFPR under Actual GDL Regimes and the Hypothetical Never a GDL Regime
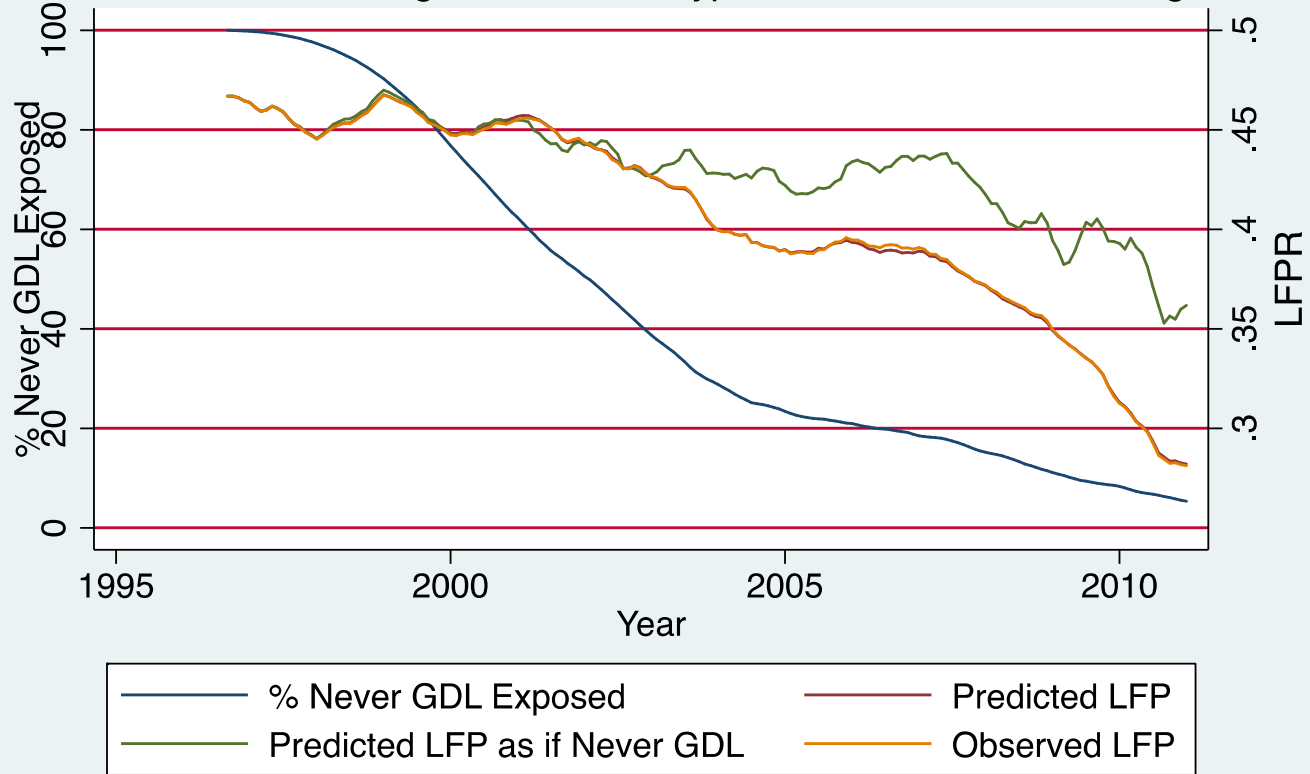

Only states observed with and without GDL restrictions; prior 12 month moving averages 
Table 1. Current Graduated Driver’s License Laws and Year of Introduction -- By State

\begin{tabular}{|c|c|c|c|c|c|c|c|c|c|}
\hline State & $\begin{array}{c}\text { Current } \\
\text { Minimum } \\
\text { Age }\end{array}$ & $\begin{array}{c}\text { Current } \\
\text { Minimum } \\
\text { Supervised } \\
\text { Hours }\end{array}$ & $\begin{array}{c}\text { Work } \\
\text { Exemptions } \\
\text { *Strict }\end{array}$ & $\begin{array}{l}\text { Year Hours } \\
\text { Restriction } \\
\text { introduced }\end{array}$ & $\begin{array}{c}\text { Current } \\
\text { Hour } \\
\text { Restriction }\end{array}$ & $\begin{array}{c}\text { Minimum } \\
\text { age at which } \\
\text { Hour } \\
\text { restriction } \\
\text { lifted }\end{array}$ & $\begin{array}{c}\text { Year } \\
\text { Passenger } \\
\text { Restriction } \\
\text { introduced }\end{array}$ & $\begin{array}{c}\text { Current } \\
\text { Passenger } \\
\text { Restriction }\end{array}$ & $\begin{array}{l}\text { Minimum age } \\
\text { at which } \\
\text { Passenger } \\
\text { restriction } \\
\text { lifted }\end{array}$ \\
\hline Alabama & 16 & 30 & Yes & 2002 & Midnight & 17 & 2002 & 1 & 17 \\
\hline Alaska & 16 & 40 & Yes & 2005 & 1 a.m. & 16.5 & 2005 & 0 & 16.5 \\
\hline Arizona & 16 & 30 & Yes & 2008 & Midnight & 16.5 & 2008 & 1 & 16.5 \\
\hline Arkansas & 16 & & Yes & 2009 & 11 p.m. & 18 & 2009 & 1 & 18 \\
\hline California & 16 & 50 & Yes* & 1998 & Midnight & 17 & 1998 & 0 & 17 \\
\hline Colorado & 16 & 50 & Yes* & 1999 & Midnight & 17 & 1999 & 0 & 17 \\
\hline Connecticut & $16,4 \mathrm{mos}$ & 40 & Yes & 2005 & Midnight & 18 & 2005 & 0 & 17.33 \\
\hline Delaware & $16,6 \mathrm{mos}$ & 50 & Yes & 1999 & $9 \mathrm{pm}$ & 17 & 1999 & 1 & 17 \\
\hline $\begin{array}{l}\text { District of } \\
\text { Columbia }\end{array}$ & $16,6 \mathrm{mos}$ & 40 & Yes & 2001 & Midnight & 18 & 2001 & 0 & 18 \\
\hline Florida & 16 & 50 & Yes & 1996 & 11 p.m. & 18 & - & - & - \\
\hline Georgia & 16 & 40 & No & 1997 & 1 a.m. & 18 & 1997 & 0 & 18 \\
\hline Hawaii & 16 & & Yes* & 2006 & 11 p.m. & 17 & 2006 & 1 & 17 \\
\hline
\end{tabular}




\begin{tabular}{|c|c|c|c|c|c|c|c|c|c|}
\hline State & $\begin{array}{c}\text { Current } \\
\text { Minimum } \\
\text { Age }\end{array}$ & $\begin{array}{c}\text { Current } \\
\text { Minimum } \\
\text { Supervised } \\
\text { Hours }\end{array}$ & $\begin{array}{c}\text { Work } \\
\text { Exemptions } \\
\text { *Strict }\end{array}$ & $\begin{array}{l}\text { Year Hours } \\
\text { Restriction } \\
\text { introduced }\end{array}$ & $\begin{array}{c}\text { Current } \\
\text { Hour } \\
\text { Restriction }\end{array}$ & $\begin{array}{c}\text { Minimum } \\
\text { age at which } \\
\text { Hour } \\
\text { restriction } \\
\text { lifted }\end{array}$ & $\begin{array}{c}\text { Year } \\
\text { Passenger } \\
\text { Restriction } \\
\text { introduced }\end{array}$ & $\begin{array}{c}\text { Current } \\
\text { Passenger } \\
\text { Restriction }\end{array}$ & $\begin{array}{c}\text { Minimum age } \\
\text { at which } \\
\text { Passenger } \\
\text { restriction } \\
\text { lifted } \\
\end{array}$ \\
\hline Idaho & 15 & 50 & No & $1995^{*}$ & Sunset & 16 & 2007 & 1 & 15.5 \\
\hline Illinois & 16 & 50 & No & 1995* & 11 p.m. & 18 & 2004 & 1 & 17 \\
\hline Indiana & $16,1 \mathrm{mo}$ & & No & 1998 & 11 p.m. & 18 & 1998 & 0 & 16.67 \\
\hline Iowa & 16 & 20 & Yes* & 1999 & 12:30 a.m. & 17 & - & - & - \\
\hline Kansas & 16 & 25 & Yes & 2010 & 9 p.m. & 16.5 & 2010 & 1 & 16.5 \\
\hline Kentucky & $16,6 \mathrm{mos}$ & 60 & Yes & 2007 & Midnight & 17 & 2007 & 1 & 17 \\
\hline Louisiana & 16 & & No & 1983 & 11 p.m. & 17 & 2001 & 1 & - \\
\hline Maine & 16 & 35 & No & 2003 & Midnight & 16.67 & 2003 & 0 & 16.67 \\
\hline Maryland & $16,3 \mathrm{mos}$ & 60 & Yes & 1995* & Midnight & 18 & 2005 & 0 & 16.9 \\
\hline Massachusetts & $16,6 \mathrm{mos}$ & 40 & No & 1995* & Midnight & 18 & 1998 & 0 & 17 \\
\hline Michigan & 16 & 50 & Yes & 1997 & Midnight & 17 & 2011 & 1 & 17 \\
\hline Minnesota & 16 & 30 & Yes & 2008 & Midnight & 16.5 & 2008 & 1 & 17 \\
\hline Mississippi & $15,6 \mathrm{mos}$ & - & Yes & 2000 & 10 p.m. & 16.5 & - & - & - \\
\hline Missouri & 16 & 40 & Yes & 2001 & 1 a.m. & 17.9 & 2006 & 1 & 17.9 \\
\hline
\end{tabular}




\begin{tabular}{|c|c|c|c|c|c|c|c|c|c|}
\hline State & $\begin{array}{c}\text { Current } \\
\text { Minimum } \\
\text { Age }\end{array}$ & $\begin{array}{c}\text { Current } \\
\text { Minimum } \\
\text { Supervised } \\
\text { Hours }\end{array}$ & $\begin{array}{c}\text { Work } \\
\text { Exemptions } \\
\text { *Strict }\end{array}$ & $\begin{array}{l}\text { Year Hours } \\
\text { Restriction } \\
\text { introduced }\end{array}$ & $\begin{array}{c}\text { Current } \\
\text { Hour } \\
\text { Restriction }\end{array}$ & $\begin{array}{c}\text { Minimum } \\
\text { age at which } \\
\text { Hour } \\
\text { restriction } \\
\text { lifted }\end{array}$ & $\begin{array}{c}\text { Year } \\
\text { Passenger } \\
\text { Restriction } \\
\text { introduced }\end{array}$ & $\begin{array}{c}\text { Current } \\
\text { Passenger } \\
\text { Restriction }\end{array}$ & $\begin{array}{l}\text { Minimum age } \\
\text { at which } \\
\text { Passenger } \\
\text { restriction } \\
\text { lifted }\end{array}$ \\
\hline Montana & 15 & 50 & Yes* & 2006 & 11 p.m. & 16 & 2006 & 1 & 16 \\
\hline Nebraska & 16 & 50 & Yes & 1999 & Midnight & 17 & 2008 & 1 & 16.5 \\
\hline Nevada & 16 & 50 & Yes* & 2005 & 10 p.m. & 18 & 2007 & 0 & 16.5 \\
\hline $\begin{array}{l}\text { New } \\
\text { Hampshire }\end{array}$ & 16 & 20 & No & 1998 & 1 a.m. & 18 & 2003 & 1 & 16.5 \\
\hline New Jersey & 17 & - & Yes* & 2001 & Midnight & 18 & 2001 & 1 & 18 \\
\hline New Mexico & $15,6 \mathrm{mos}$ & 50 & Yes* & 2000 & Midnight & 16.5 & 2000 & 1 & 16.5 \\
\hline New York & $16,6 \mathrm{mos}$ & 20 & Yes & 1995* & 9 p.m. & 17 & 2003 & 1 & 17 \\
\hline North Carolina & 16 & - & Yes & 1997 & 9 p.m. & 16.5 & 2001 & 1 & 16.5 \\
\hline North Dakota & 16 & - & Yes & 2012 & 9 p.m. & 16 & - & - & - \\
\hline Ohio & 16 & 50 & Yes* & 1999 & 1 a.m. & 18 & 2007 & 1 & 17 \\
\hline Oklahoma & 16 & 40 & Yes & 2005 & 10 p.m. & 16.5 & 2005 & 1 & 16.5 \\
\hline Oregon & 16 & 50 & Yes & 2000 & Midnight & 17 & 2000 & 0 & 17 \\
\hline Pennsylvania & $16,6 \mathrm{mos}$ & 50 & Yes & 1991 & 11 p.m. & 17 & 2011 & 1 & 17 \\
\hline
\end{tabular}




\begin{tabular}{|c|c|c|c|c|c|c|c|c|c|}
\hline State & $\begin{array}{c}\text { Current } \\
\text { Minimum } \\
\text { Age }\end{array}$ & $\begin{array}{c}\text { Current } \\
\text { Minimum } \\
\text { Supervised } \\
\text { Hours }\end{array}$ & $\begin{array}{c}\text { Work } \\
\text { Exemptions } \\
\text { *Strict }\end{array}$ & $\begin{array}{l}\text { Year Hours } \\
\text { Restriction } \\
\text { introduced }\end{array}$ & $\begin{array}{c}\text { Current } \\
\text { Hour } \\
\text { Restriction }\end{array}$ & $\begin{array}{c}\text { Minimum } \\
\text { age at which } \\
\text { Hour } \\
\text { restriction } \\
\text { lifted }\end{array}$ & $\begin{array}{c}\text { Year } \\
\text { Passenger } \\
\text { Restriction } \\
\text { introduced }\end{array}$ & $\begin{array}{c}\text { Current } \\
\text { Passenger } \\
\text { Restriction }\end{array}$ & $\begin{array}{c}\text { Minimum age } \\
\text { at which } \\
\text { Passenger } \\
\text { restriction } \\
\text { lifted } \\
\end{array}$ \\
\hline Rhode Island & $16,6 \mathrm{mos}$ & 50 & Yes & 1999 & 1 a.m. & 17.5 & 2005 & 1 & 18.5 \\
\hline South Carolina & $15,6 \mathrm{mos}$ & 40 & Yes & $1995^{*}$ & 8 p.m. & 16.5 & 2002 & 2 & 16.5 \\
\hline South Dakota & $14,6 \mathrm{mos}$ & - & No & 2004 & 10 p.m. & 16 & - & - & - \\
\hline Tennessee & 16 & 50 & No & 2001 & 11 p.m. & 17 & 2001 & 1 & 17 \\
\hline Texas & 16 & - & Yes & 2002 & Midnight & 18 & 2002 & 1 & 18 \\
\hline Utah & 16 & 40 & Yes & 1999 & Midnight & 17 & 2001 & 0 & 16.5 \\
\hline Vermont & 16 & 40 & No & - & - & - & 2000 & 0 & 16.5 \\
\hline Virginia & $16,3 \mathrm{mos}$ & 45 & Yes & 2001 & Midnight & 18 & 1998 & 1 & 18 \\
\hline Washington & 16 & 50 & No & 2001 & 1 a.m. & 17 & 2001 & 0 & 17 \\
\hline West Virginia & 16 & 30 & Yes & 2001 & 11 p.m. & 17 & 2001 & 0 & 17 \\
\hline Wisconsin & 16 & 30 & Yes & 2000 & Midnight & 16.67 & 2000 & 1 & 16.67 \\
\hline Wyoming & 16 & 50 & Yes* & 2005 & 11 p.m. & 16.5 & 2005 & 1 & 16.5 \\
\hline
\end{tabular}

${ }^{*}$ Compiled using data provided by the Insurance Institute for Highway Safety, IIHS, 2008 
Table 2a

Summary Statistics: Current Population Survey

\begin{tabular}{|l|c|c|}
\hline & Male & Female \\
\hline Integer Age (15-18) & 16.798 & 16.748 \\
& $(0.762)$ & $(0.740)$ \\
\hline Non-Hispanic Black & 0.117 & 0.119 \\
& $(0.321)$ & $(0.324)$ \\
\hline Hispanic & 0.147 & 0.149 \\
& $(0.355)$ & $(0.356)$ \\
\hline Non-Hispanic Other & 0.067 & 0.063 \\
& $(0.251)$ & $(0.237)$ \\
\hline Labor Force Participation & 0.380 & 0.383 \\
& $(0.485)$ & $(0.486)$ \\
\hline Hours| Hours>0 & 20.488 & 17.877 \\
& $(11.786)$ & $(9.788)$ \\
& {$[\mathrm{n}=118,220]$} & {$[\mathrm{n}=113,295]$} \\
\hline $\mathrm{n}$ & 394,034 & 358,6000 \\
\hline
\end{tabular}

Table 2b

Summary Statistics: Weighted Average of GDL Exposure Probabilities

\begin{tabular}{|l|c|c|}
\hline GDL Exposure & Male & Female \\
\hline Restricted & 29.172 & 30.751 \\
& $(43.444)$ & $(44.049)$ \\
\hline Formerly Restricted & 35.368 & 34.381 \\
& $(45.801)$ & $(45.384)$ \\
\hline Never Restricted & 35.460 & 34.869 \\
& $(47.293)$ & $(47.119)$ \\
\hline
\end{tabular}

*Source: Monthly Current Population Surveys, January 1995-December 2014. Youth aged 15-18, with no inconsistencies in reported ages across survey rounds. 
Table 3. Differential Probabilities in Labor Force Participation by GDL Exposure and Gender

\begin{tabular}{|l|c|c|c|c|}
\hline \multirow{2}{*}{ Restriction } & \multicolumn{2}{|c|}{ Current vs Never Covered } & \multicolumn{2}{l|}{ Former vs. Never Covered } \\
\hline & Male & Female & Male & Female \\
\hline Any GDL & $-0.071^{* *}$ & $-0.054^{* *}$ & $-0.063^{* *}$ & $-0.049^{*}$ \\
\hline & $(0.025)$ & $(0.026)$ & $(0.024)$ & $(0.025)$ \\
\hline No Exemptions & $-0.075^{* *}$ & $-0.089^{* *}$ & $-0.070^{* *}$ & $-0.061^{*}$ \\
\hline $\begin{array}{l}\text { Any Work } \\
\text { Exemption }\end{array}$ & $(0.031)$ & $(0.032)$ & $(0.029)$ & $(0.032)$ \\
\hline & $-0.070^{* *}$ & $-0.046^{*}$ & $-0.061^{* *}$ & $-0.047^{*}$ \\
\hline $\begin{array}{l}\text { Minor Work } \\
\text { Exemption }\end{array}$ & $-0.068^{* *}$ & $-0.046^{*}$ & $-0.064^{* *}$ & $-0.048^{*}$ \\
\hline & $(0.025)$ & $(0.026)$ & $(0.025)$ & $(0.026)$ \\
\hline $\begin{array}{l}\text { Strict Work } \\
\text { Exemption }\end{array}$ & $-0.072^{* *}$ & $-0.047^{*}$ & $-0.057^{* *}$ & $-0.043^{*}$ \\
\hline & $(0.027)$ & $(0.028)$ & $(0.025)$ & $(0.026)$ \\
\hline $\begin{array}{l}\text { Mean Rate for } \\
\begin{array}{l}\text { Treated } \\
\text { Individuals }\end{array}\end{array}$ & 0.270 & 0.284 & 0.392 & 0.400 \\
\hline
\end{tabular}

$* * * \mathrm{p}<.01 ; * * \mathrm{p}<.05 ; * \mathrm{p}<.10$; Standard errors clustered by state-month are in parentheses.

Weighted averages of the impacts of various forms of GDL restrictions on labor force participation using the regression model estimates from the CPS data. For the first two columns, these effects are calculated using the differences in the estimated coefficients between the currently-covered and the never-covered regression functions, evaluated at the observed characteristics for currently-covered, driving-aged teens in states with GDL restrictions as listed in the row label. The last two columns contain similar comparisons between those formerly restricted and those never restricted, using the distribution of characteristics for formerly restricted teens. Note that the distribution of states and time periods vary across rows in this table. See text for more detailed information on the procedures used in this table. 
Table 4. Differences in Hours of Work (Conditional on Hours Positive) by GDL Exposure and Gender

\begin{tabular}{|l|c|c|c|c|}
\hline Restriction & \multicolumn{2}{|c|}{ Current vs Never Covered } & \multicolumn{2}{c|}{ Former vs. Never Covered } \\
\hline & Male & Female & Male & Female \\
\hline Any GDL & $2.427^{* *}$ & 0.389 & $1.616^{*}$ & -0.418 \\
\hline No Exemptions & $(0.901)$ & $(0.800)$ & $(0.859)$ & $(0.759)$ \\
\hline & $3.639^{* *}$ & 0.944 & $2.437^{* *}$ & -0.075 \\
\hline $\begin{array}{l}\text { Any Work } \\
\text { Exemption }\end{array}$ & $2.134^{* *}$ & $0.974)$ & $(0.998)$ & $(0.900)$ \\
\hline $\begin{array}{l}\text { Minor Work } \\
\text { Exemption }\end{array}$ & $(0.894)$ & $(0.796)$ & $(0.866)$ & -0.479 \\
\hline $\begin{array}{l}\text { Strict Work } \\
\text { Exemption }\end{array}$ & $(0.891)$ & $(0.806)$ & $(0.887)$ & $(0.761)$ \\
\hline & $1.992^{* *}$ & 0.204 & 1.036 & -0.468 \\
\hline $\begin{array}{l}\text { Mean Rate for } \\
\text { Treated } \\
\text { Individuals }\end{array}$ & $(1.009)$ & $(0.876)$ & $(0.937)$ & $(0.804)$ \\
\hline
\end{tabular}

${ }_{* * *} \mathrm{p}<.01 ;{ }^{* *} \mathrm{p}<.05 ;{ }^{*} \mathrm{p}<.10$; Standard errors clustered by state-month are in parentheses. Weighted averages of the impacts of various forms of GDL restrictions on hours of work conditional on working using the regression model estimates from the CPS data. For the first two columns, effects are calculated using the differences in the estimated coefficients between the currently covered and the never covered regression functions, evaluated at the observed characteristics for currently covered, driving aged teens in states with GDL restrictions as listed in the row label. The last two columns contain similar comparisons between those formerly restricted and those never restricted, using the distribution of characteristics for formerly restricted teens. Note that the distribution of states and time periods vary across rows in this table. See text for more detailed information on the procedures used in this table. 
Table 5. Differential Probabilities in Labor Force Participation for Non-Metro teens by GDL Exposure and Gender

\begin{tabular}{|l|c|c|c|c|}
\hline \multirow{2}{*}{ Restriction } & \multicolumn{2}{|c|}{ Current vs Never Covered } & \multicolumn{2}{l|}{ Former vs. Never Covered } \\
\hline & Male & Female & Male & Female \\
\hline Any GDL & -0.025 & $-0.087^{*}$ & -0.02 & $-0.080^{*}$ \\
\hline No Exemptions & $(0.042)$ & $(0.046)$ & $(0.040)$ & $(0.043)$ \\
\hline & 0.01 & $-0.118^{* *}$ & 0.016 & -0.075 \\
\hline $\begin{array}{l}\text { Any Work } \\
\text { Exemption }\end{array}$ & $-0.048)$ & $(0.051)$ & $(0.048)$ & $(0.053)$ \\
\hline $\begin{array}{l}\text { Minor Work } \\
\text { Exemption }\end{array}$ & -0.061 & -0.073 & -0.033 & $-0.081^{*}$ \\
\hline & $(0.042)$ & $(0.047)$ & $(0.041)$ & $(0.044)$ \\
\hline $\begin{array}{l}\text { Strict Work } \\
\text { Exemption }\end{array}$ & -0.004 & $-0.078^{*}$ & -0.043 & $-0.089^{*}$ \\
\hline & $(0.054)$ & $(0.046)$ & $(0.043)$ & $(0.047)$ \\
\hline $\begin{array}{l}\text { Mean Rate for } \\
\begin{array}{l}\text { Treated } \\
\text { Individuals }\end{array}\end{array}$ & 0.323 & 0.329 & -0.012 & -0.064 \\
\hline
\end{tabular}

*** $\mathrm{p}<.01 ;{ }^{* *} \mathrm{p}<.05 ;{ }^{*} \mathrm{p}<.10$; Standard errors clustered by state-month are in parentheses.

${ }^{*}$ Weighted averages of the impacts of various forms of GDL restrictions on labor force participation using the regression model estimates from the CPS data using only individuals residing in non-metropolitan areas. For the first two columns, effects are calculated using the differences in the estimated coefficients between the currently covered and the never covered regression functions, evaluated at the observed characteristics for currently covered, driving aged teens in non-metro areas. The last two columns contain similar comparisons between those formerly restricted and those never restricted, using the distribution of characteristics for formerly restricted teens. Note that the distribution of states and time periods vary across rows in this table. See text for more detailed information on the procedures used in this table. 
Table 6a. Differential Probabilities in Labor Force Participation, unweighted by GDL Exposure and Gender

Covered vs. never Covered

\begin{tabular}{|l|c|c|c|c|}
\hline Restriction & \multicolumn{2}{|c|}{ Weighted } & \multicolumn{2}{c|}{ Unweighted } \\
\hline & Male & Female & Male & Female \\
\hline Any GDL & $-0.071^{* *}$ & $-0.054^{* *}$ & $-0.055^{* *}$ & $-0.071^{* *}$ \\
\hline & $(0.025)$ & $(0.026)$ & $(0.025)$ & $(0.026)$ \\
\hline No Exemptions & $-0.075^{* *}$ & $-0.089^{* *}$ & $-0.063^{* *}$ & $-0.102^{* *}$ \\
\hline $\begin{array}{l}\text { Any Work } \\
\text { Exemption }\end{array}$ & $(0.031)$ & $(0.032)$ & $(0.031)$ & $(0.033)$ \\
\hline $\begin{array}{l}\text { Minor Work } \\
\text { Exemption }\end{array}$ & $-0.070^{* *}$ & $-0.046^{*}$ & $-0.054^{* *}$ & $-0.064^{* *}$ \\
\hline & $-0.068^{* *}$ & $-0.046^{*}$ & $-0.056^{* *}$ & $-0.067^{* *}$ \\
\hline $\begin{array}{l}\text { Strict Work } \\
\text { Exemption }\end{array}$ & $-0.072^{* *}$ & $-0.047^{*}$ & $-0.050^{*}$ & $-0.059^{* *}$ \\
\hline & $(0.027)$ & $(0.028)$ & $(0.027)$ & $(0.028)$ \\
\hline $\begin{array}{l}\text { Mean Rate for } \\
\text { Treated } \\
\text { Individuals }\end{array}$ & 0.270 & 0.284 & 0.273 & 0.288 \\
\hline
\end{tabular}

Table 6b. Differential Probabilities in Labor Force Participation, unweighted by GDL Exposure and Gender

Formerly Covered vs. never Covered

\begin{tabular}{|l|c|c|c|c|}
\hline Restriction & \multicolumn{2}{|c|}{ Weighted } & \multicolumn{2}{c|}{ Unweighted } \\
\hline Any GDL & $-0.063^{* *}$ & $-0.049^{*}$ & -0.033 & -0.035 \\
\hline & $(0.024)$ & $(0.025)$ & $(0.027)$ & $(0.028)$ \\
\hline No Exemptions & $-0.070^{* *}$ & $-0.061^{*}$ & -0.034 & -0.060 \\
\hline $\begin{array}{l}\text { Any Work } \\
\text { Exemption }\end{array}$ & $(0.029)$ & $(0.032)$ & $(0.035)$ & $(0.037)$ \\
\hline $\begin{array}{l}\text { Minor Work } \\
\text { Exemption }\end{array}$ & $-0.061^{* *}$ & $-0.047^{*}$ & -0.032 & -0.029 \\
\hline & $(0.024)$ & $(0.025)$ & $(0.026)$ & $(0.027)$ \\
\hline $\begin{array}{l}\text { Strict Work } \\
\text { Exemption }\end{array}$ & $-0.064^{* *}$ & $-0.048^{*}$ & -0.033 & -0.031 \\
\hline & $(0.025)$ & $(0.026)$ & $(0.026)$ & $(0.028)$ \\
\hline $\begin{array}{l}\text { Mean Rate for } \\
\text { Treated } \\
\text { Individuals }\end{array}$ & $-0.057^{* *}$ & $-0.043^{*}$ & -0.031 & -0.026 \\
\hline
\end{tabular}

${ }^{* * *} \mathrm{p}<.01$; ${ }^{* *} \mathrm{p}<.05 ;{ }^{*} \mathrm{p}<.10$; Standard errors clustered by state-month are in parentheses. 
${ }^{*}$ Comparison of effects estimated by assuming every observation is exactly integer age plus six months old the week before the survey and effects estimated by the probabilistic weighting approach described in the text. Weighted averages of the impacts of various forms of GDL restrictions on labor force participation using the regression model estimates from the CPS data. For the first two columns, these effects are calculated using the differences in the estimated coefficients between the currently covered and the never covered regression functions, evaluated at the observed characteristics for currently covered, driving aged teens in states with GDL restrictions as listed in the row label. The last two columns contain similar comparisons between those formerly restricted and those never restricted, using the distribution of characteristics for formerly restricted teens. Note that the distribution of states and time periods vary across rows in this table. See text for more detailed information on the procedures used in this table. 


\section{Appendix One \\ Citations for State DMVs used to determine Work Exemptions}

http://doa.alaska.gov/dmv/akol/teenlaw.htm

https://www.alabamapublichealth.gov/teendriving/graduated-drivers-license.html

https://www.dfa.arkansas.gov/driver-services/frequently-asked-questions/\#k

https://www.azdot.gov/motor-vehicles/driver-services/teen-drivers/permit-and-license-requirements

https://www.dmv.ca.gov/portal/dmv/detail/pubs/hdbk/minors

https://www.codot.gov/safety/colorado-teen-drivers/parent/teen-driving-restrictions.html

https://www.ct.gov/dmv/cwp/view.asp?a=805\&q=424252

https://dmv.dc.gov/node/1119181

https://www.dmv.de.gov/services/driver services/drivers license/dr lic grad dl.shtml

https://www.flhsmv.gov/driver-licenses-id-cards/licensing-requirements-teens-graduated-driver-

license-laws-driving-curfews/

https://dds.georgia.gov/teen-drivers

https://www.drivinglaws.org/resources/hawaii-teen-driving.html

https://iowadot.gov/mvd/resources/MM689 IntermediateLicense Card.pdf

https://www.dmv.org/id-idaho/teen-drivers.php

http://www.cyberdriveillinois.com/departments/drivers/teen driver safety/gdl.html

https://www.in.gov/bmv/files/Driver Guide for Parents and Teens.pdf

https://www.ksrevenue.org/dovgdl.html

https://drive.ky.gov/driver-licensing/Pages/Graduated-Driver-Licensing-Program.aspx

https://expresslane.dps.louisiana.gov/CDLForms/Graduated\%20Licensing\%20program.pdf

https://www.mass.gov/service-details/teen-drivers

http://www.mva.maryland.gov/drivers/rookie-driver/general-provisional.htm\#provisionalrestrictions

https://www.maine.gov/sos/bmv/licenses/graduatedlic.html 
https://www.michigan.gov/sos/0,4670,7-127-1627 $601696017584274---, 00 . h t m l$

https://www.revisor.mn.gov/statutes/cite/171.055

https://dor.mo.gov/drivers/teens/gradlaw.php

http://www.driverservicebureau.dps.ms.gov/Drivers/Intermediate License Class Y

https://dojmt.gov/driving/driver-licensing/

https://www.ncdot.gov/dmv/license-id/driver-licenses/new-drivers/Pages/graduated-licensing.aspx

https://www.ndhealth.gov/injury/Publications/ND Teen Licensing.pdf

https://dmv.nebraska.gov/dl/overview-graduated-drivers-licensing

https://www.nh.gov/safety/divisions/dmv/driver-licensing/apply/youth-operator.htm

https://www.state.nj.us/mvc/license/initiallicense.htm

http://www.mvd.newmexico.gov/apply-for-a-learner-s-permit.aspx

http://www.dmvnv.com/nvdlteens.htm

https://dmv.ny.gov/driver-license/upstate-new-york-junior-driver-license-restrictions

http://www.bmv.ohio.gov/dl-gdl.aspx

https://www.ok.gov/dps/Obtain an Oklahoma Driver License ID Card/Applying for an Original Driv er License (Under the Age of 18)/Graduated Driver License.html

https://www.oregon.gov/ODOT/DMV/TEEN/pages/license.aspx

https://www.dot.state.pa.us/Public/DVSPubsForms/BDL/BDL\%20Fact\%20Sheets/fs-wy.pdf

http://www.dmv.ri.gov/documents/manuals/Driver Manual FINAL.pdf

http://www.scdmvonline.com/Driver-Services/Drivers-License/First-Time-Driver

https://dps.sd.gov/driver-licensing/south-dakota-licensing-information/teen-drivers

https://www.tn.gov/content/dam/tn/safety/documents/GDLBroc.pdf

https://www.dps.texas.gov/DriverLicense/gdl.htm

https://dld.utah.gov/minorteen-restrictions/

https://www.dmv.virginia.gov/drivers/\#restrictions.asp

$\underline{\text { http://dmv.vermont.gov/licenses/new/junior-drivers-license/graduated-license-laws }}$ 
$\underline{\text { https://www.dol.wa.gov/driverslicense/teens.html }}$

https://wisconsindot.gov/Documents/dmv/shared/gdl-summary.pdf

https://transportation.wv.gov/DMV/DMVFormSearch/Drivers Licensing Handbook web.pdf

http://www.dot.state.wy.us/home/driver license records/new licenses/learner permits.html 


\section{AL: LFP Pre-Trends}

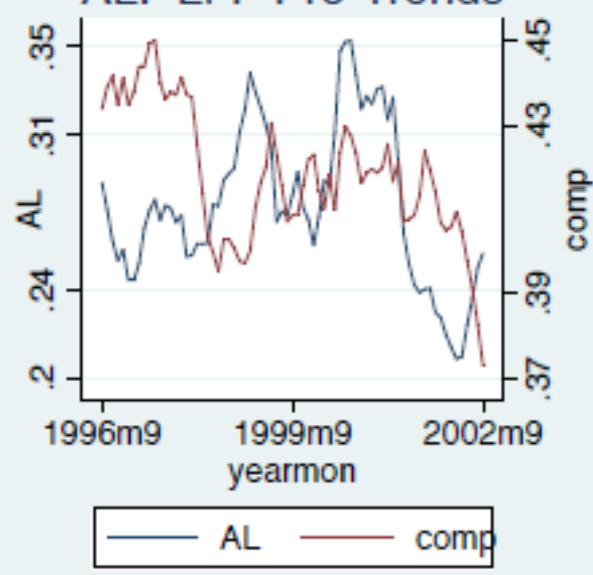

AK: LFP Pre-Trends

AZ: LFP Pre-Trends
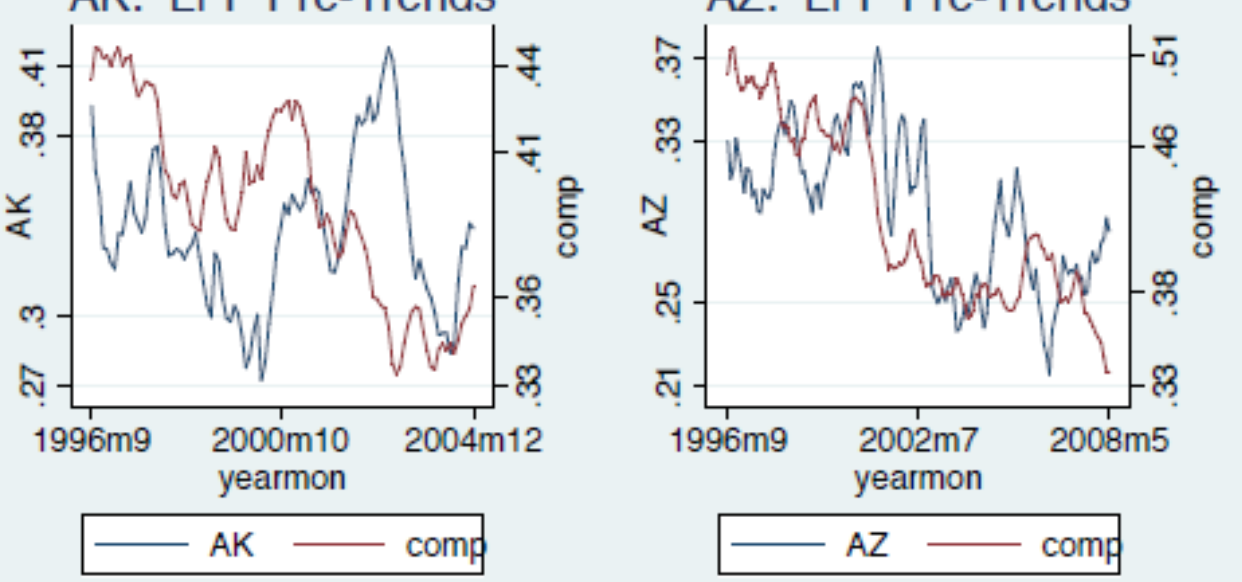

\section{AR: LFP Pre-Trends}

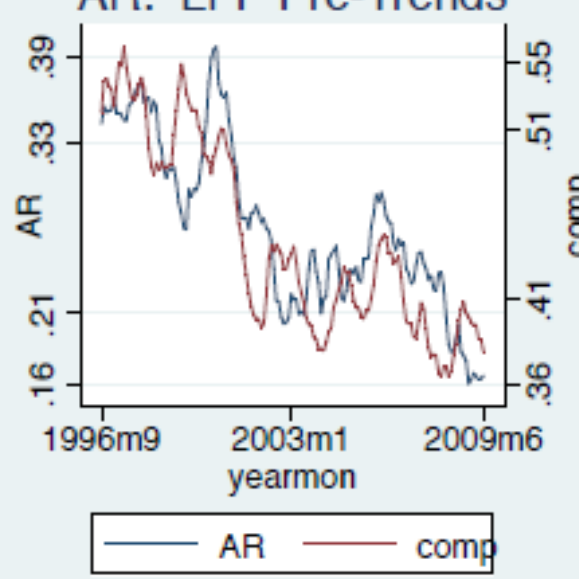

CA: LFP Pre-Trends

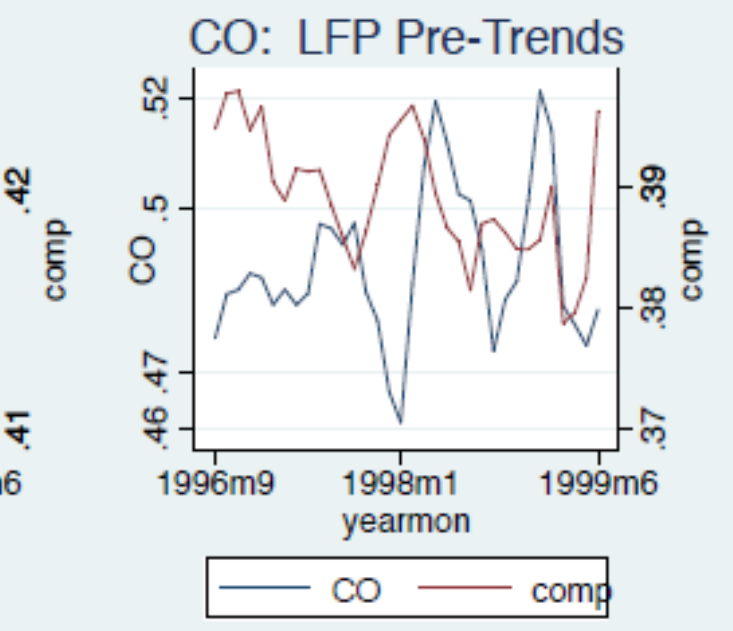



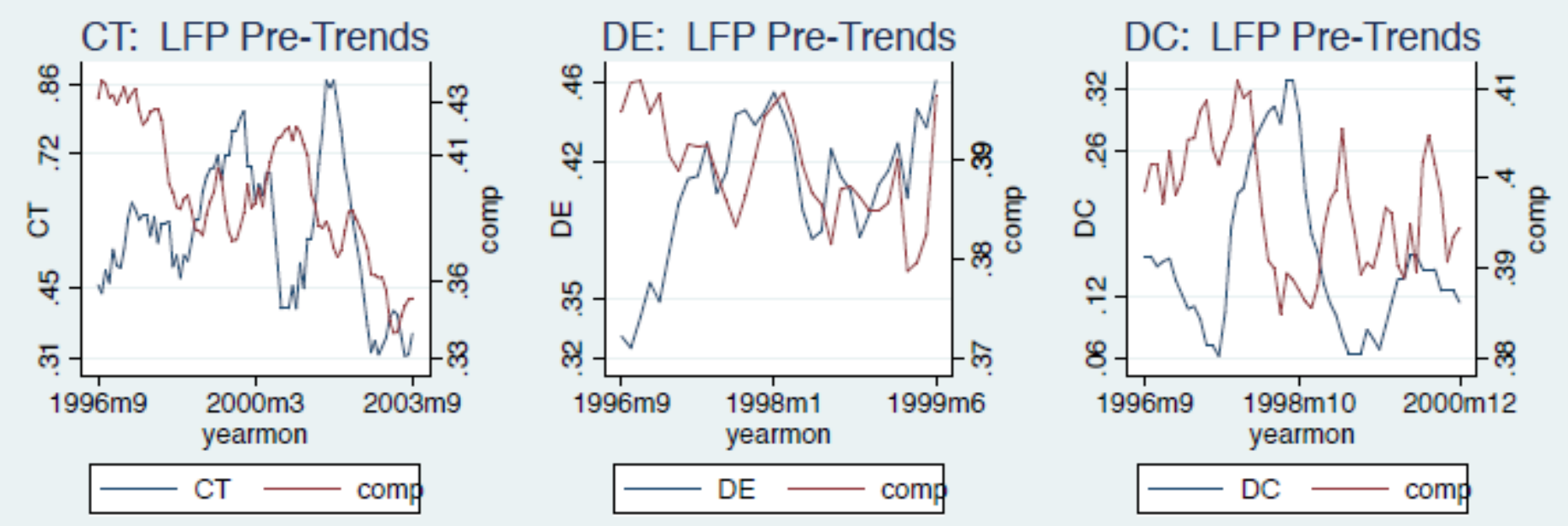

\section{GA: LFP Pre-Trends}

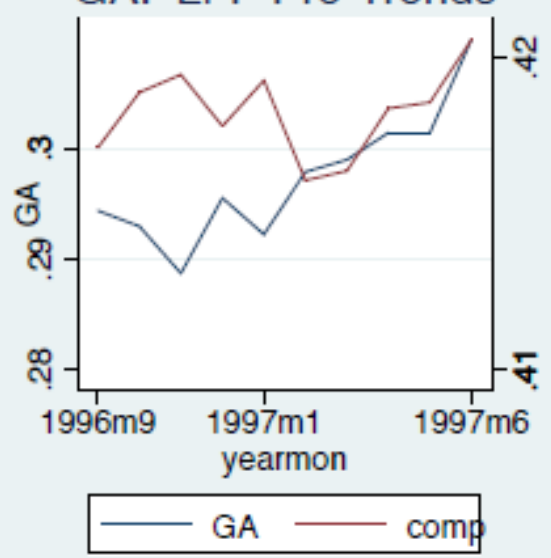

HI: LFP Pre-Trends

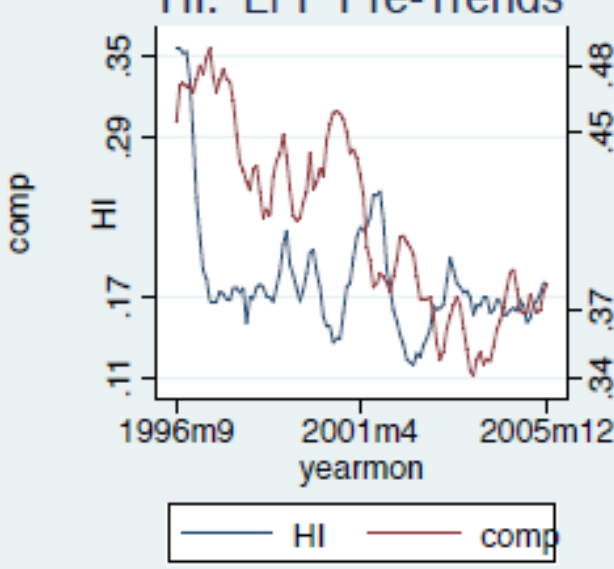

IN: LFP Pre-Trends

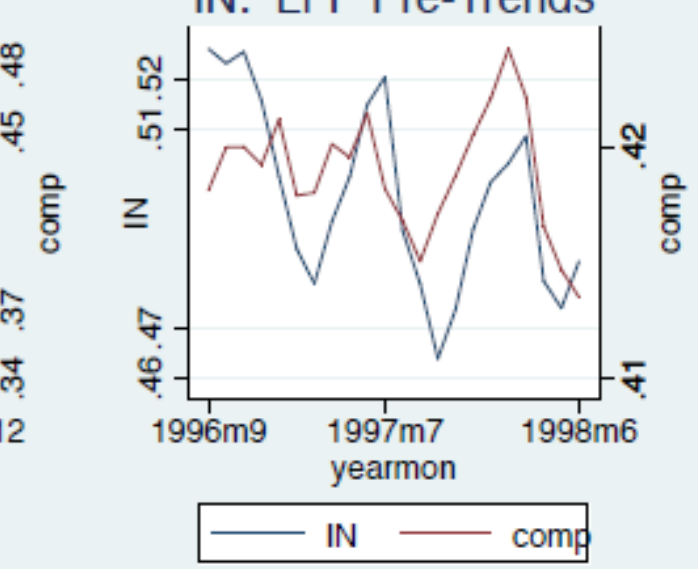


IA: LFP Pre-Trends

KS: LFP Pre-Trends
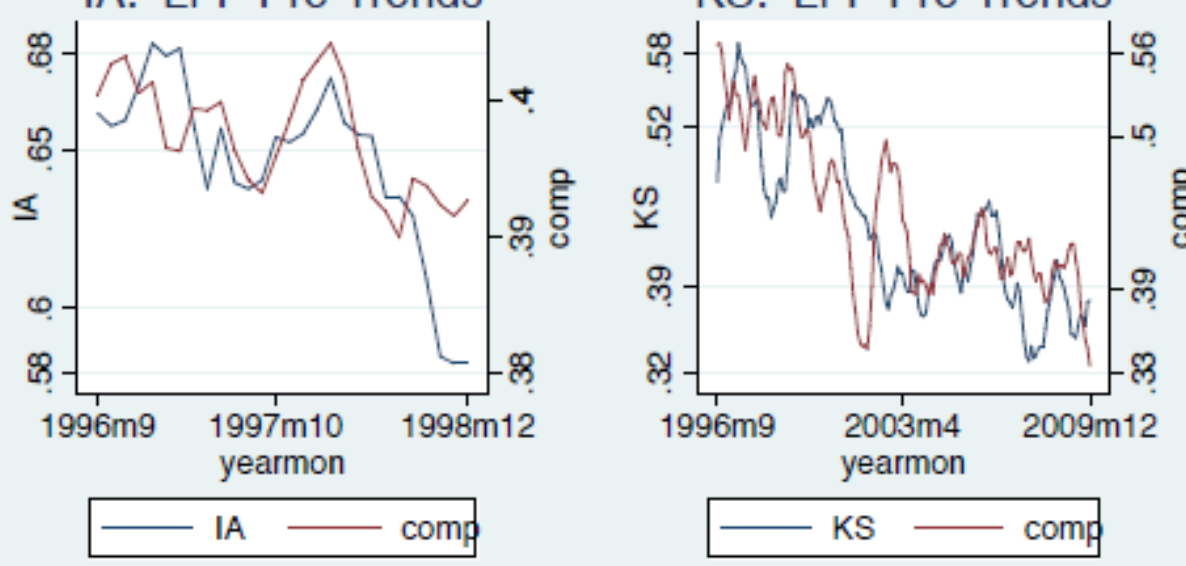

KY: LFP Pre-Trends

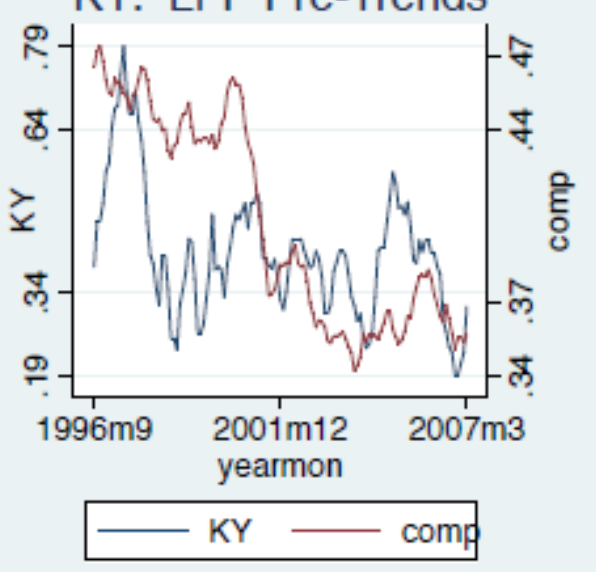

ME: LFP Pre-Trends

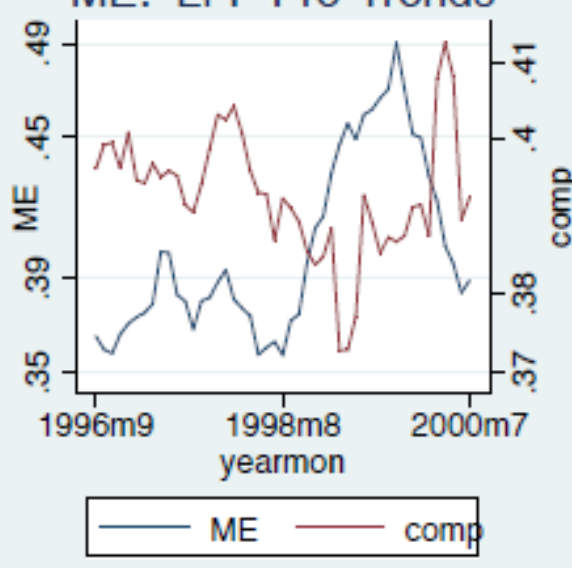

MI: LFP Pre-Trends

MN: LFP Pre-Trends
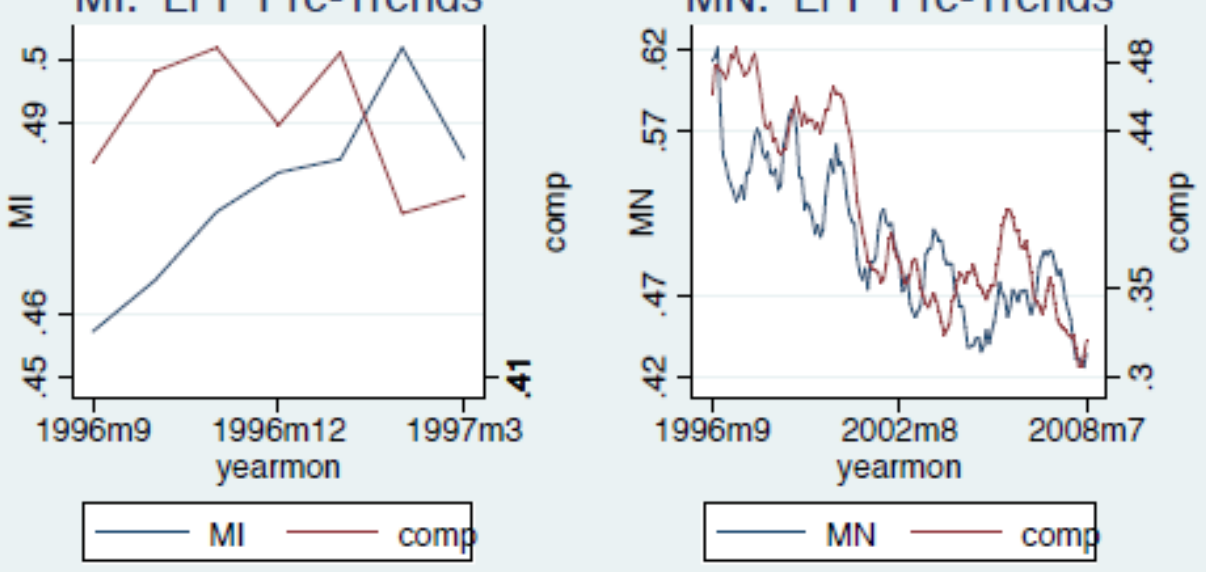
MS: LFP Pre-Trends

MO: LFP Pre-Trends
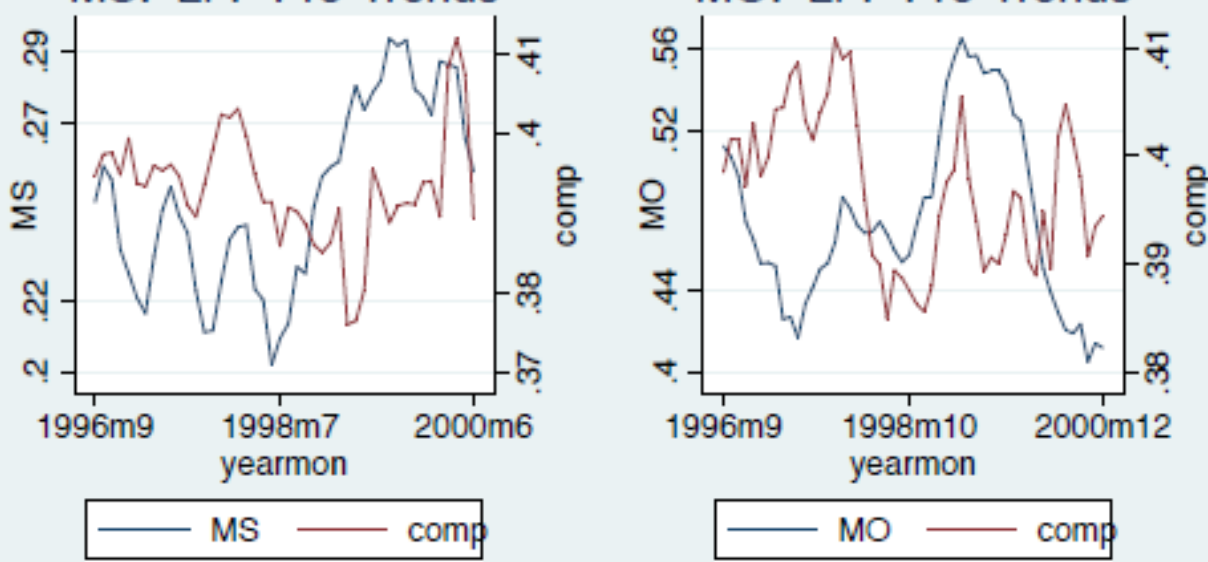

MT: LFP Pre-Trends

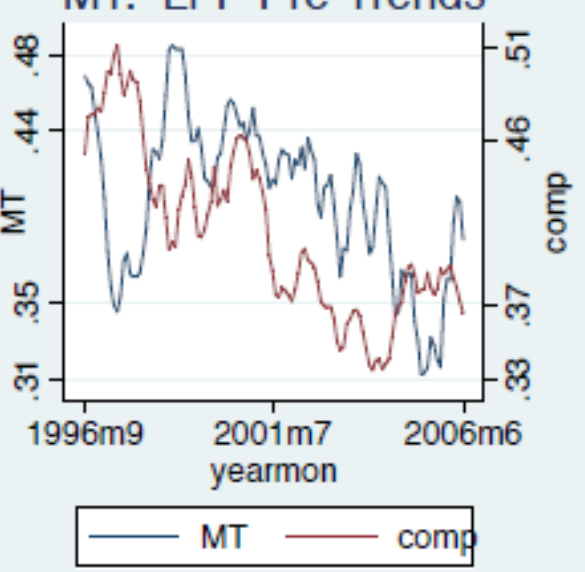

NE: LFP Pre-Trends

NV: LFP Pre-Trends
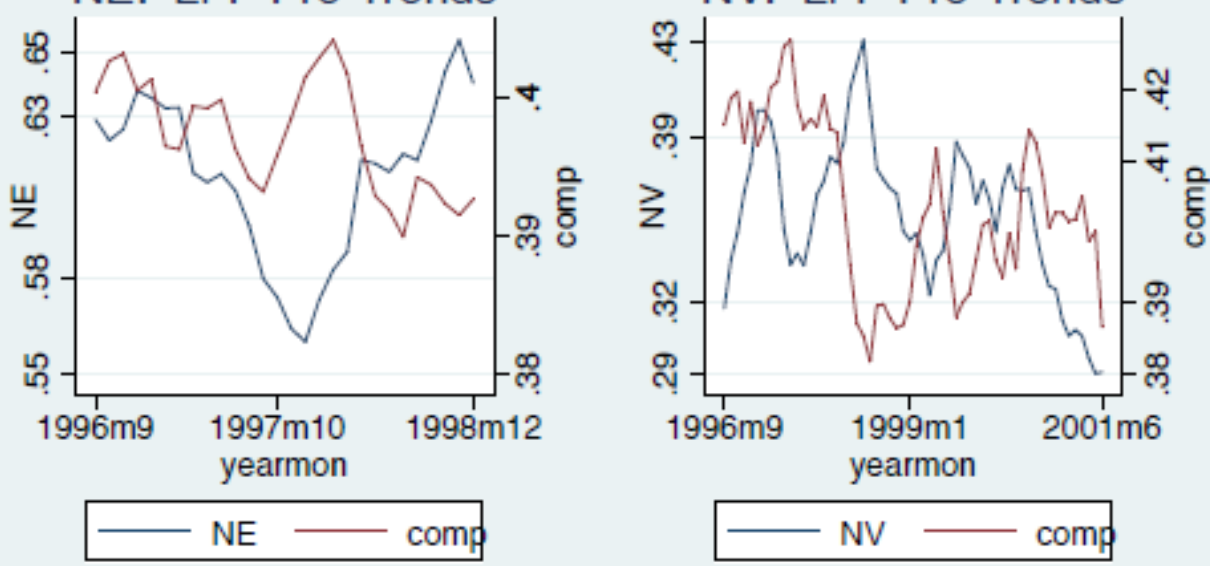

NH: LFP Pre-Trends

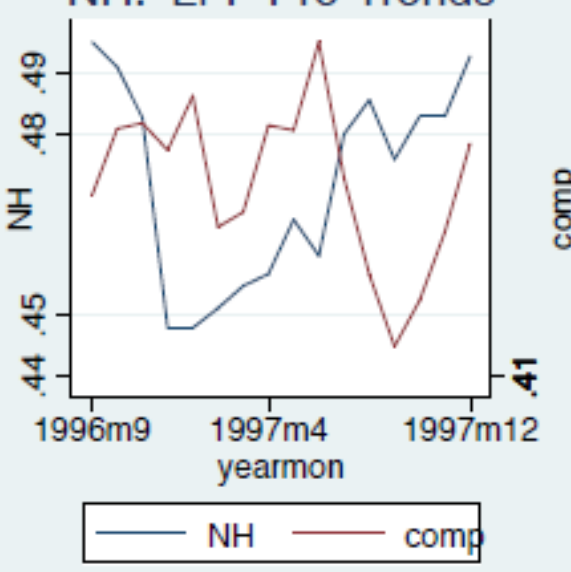



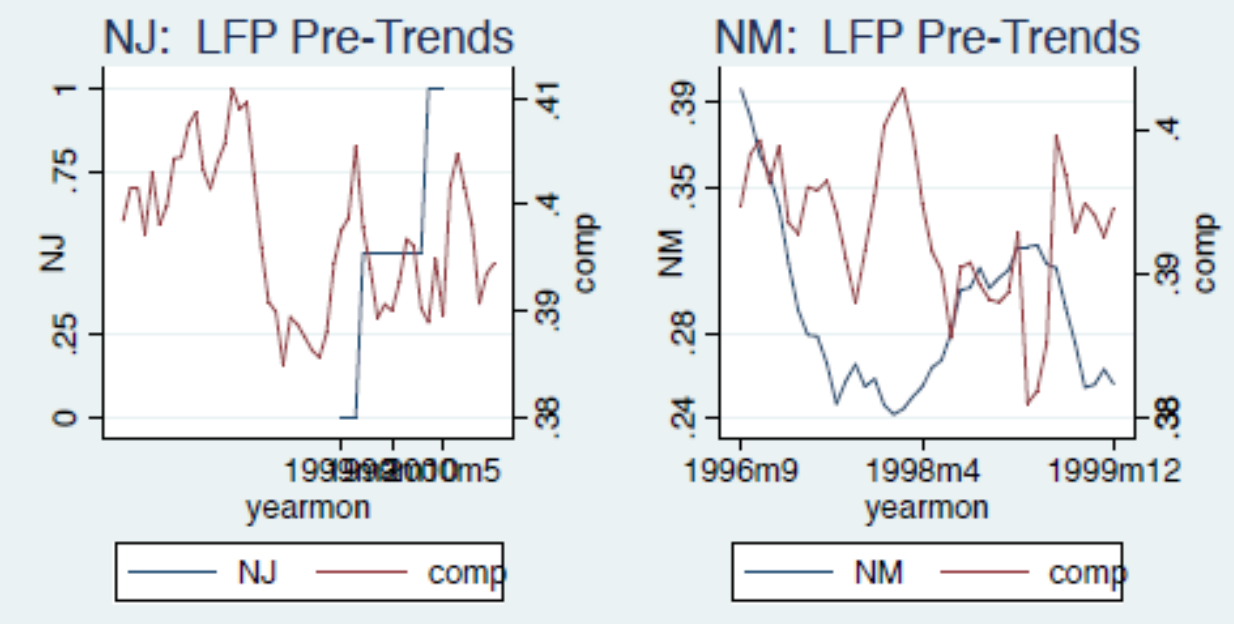

NC: LFP Pre-Trends

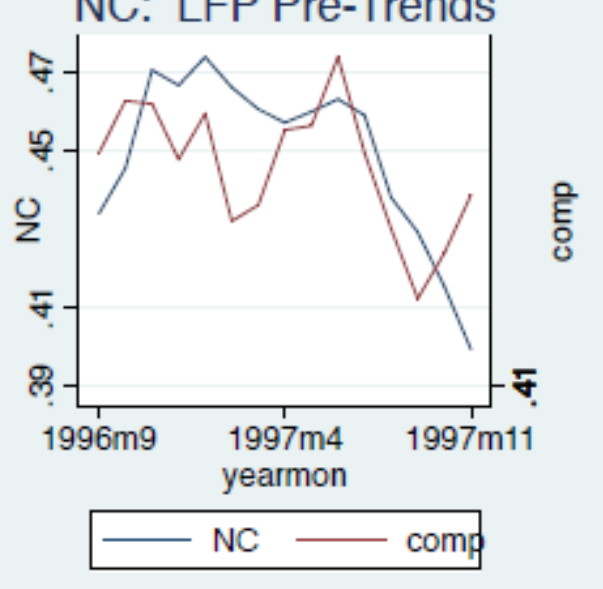

$\mathrm{OH}$ : LFP Pre-Trends

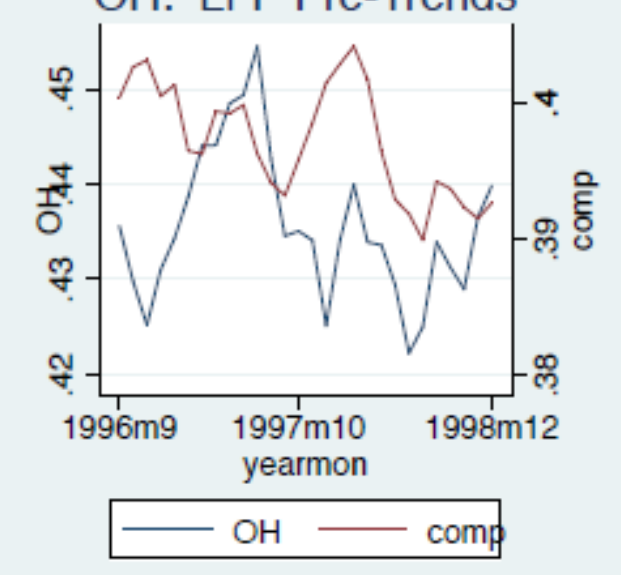

OK: LFP Pre-Trends

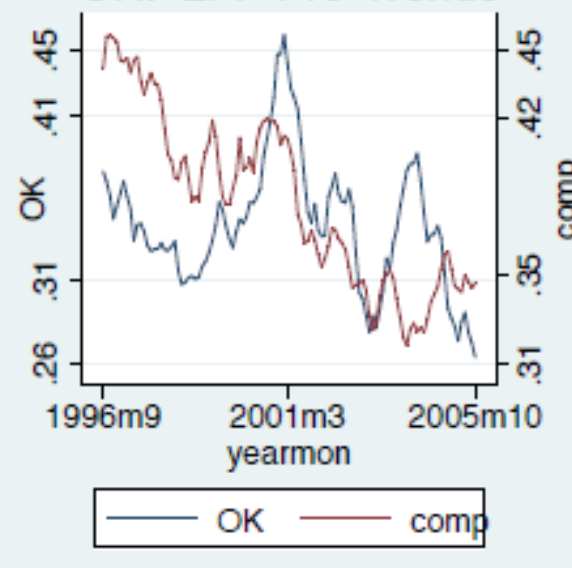

OR: LFP Pre-Trends

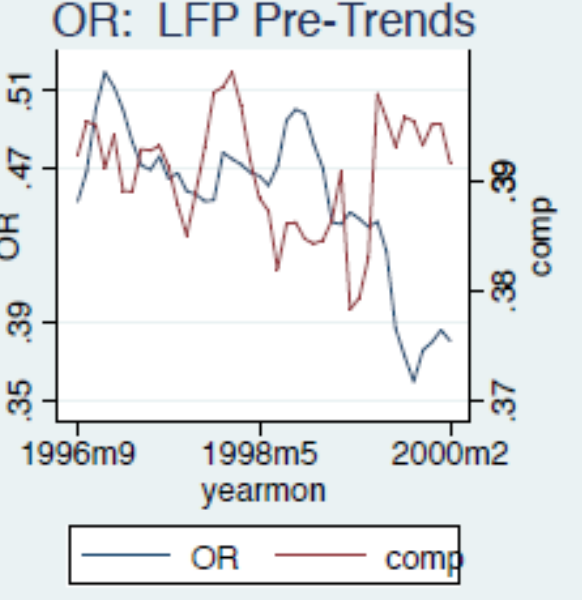



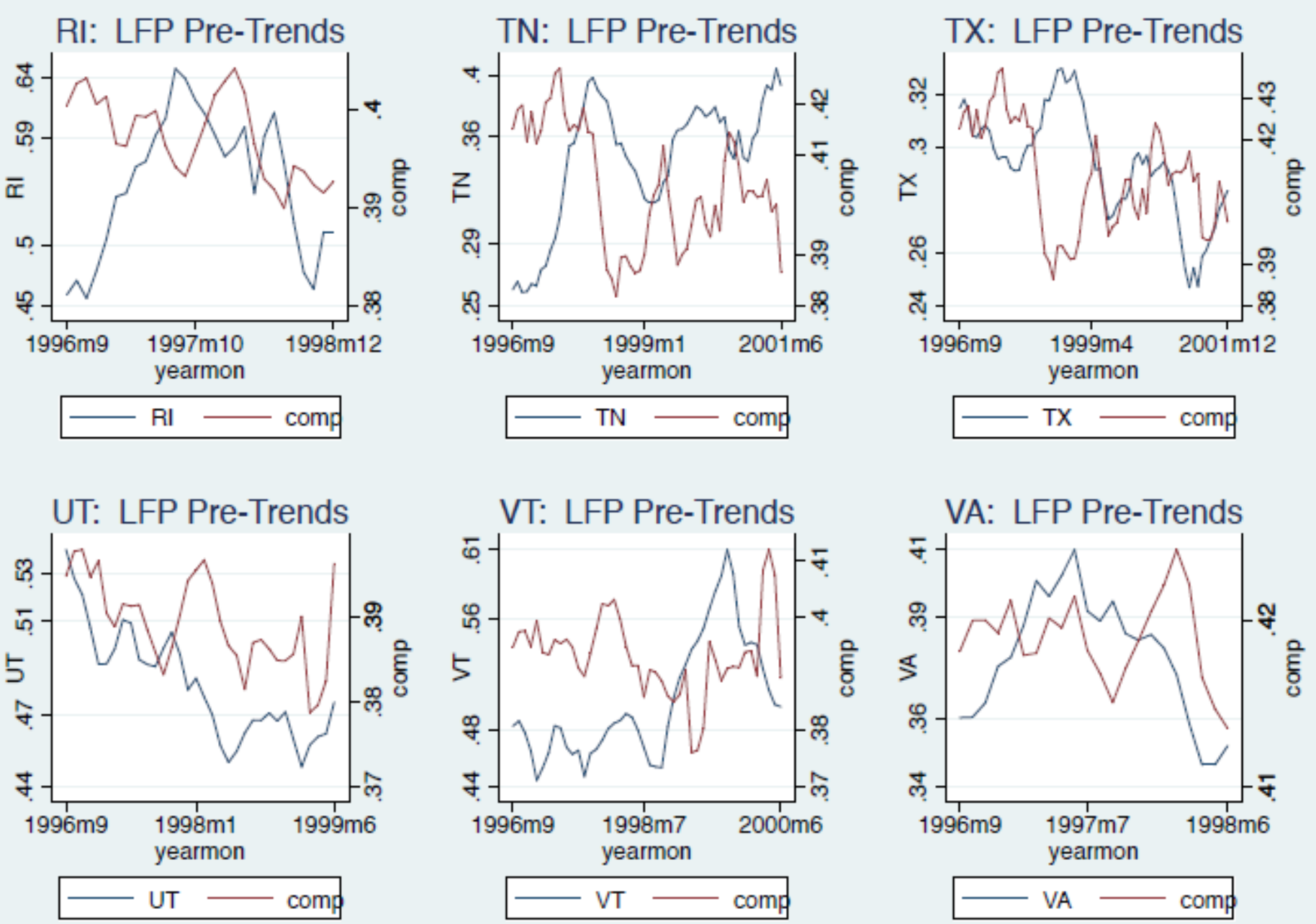

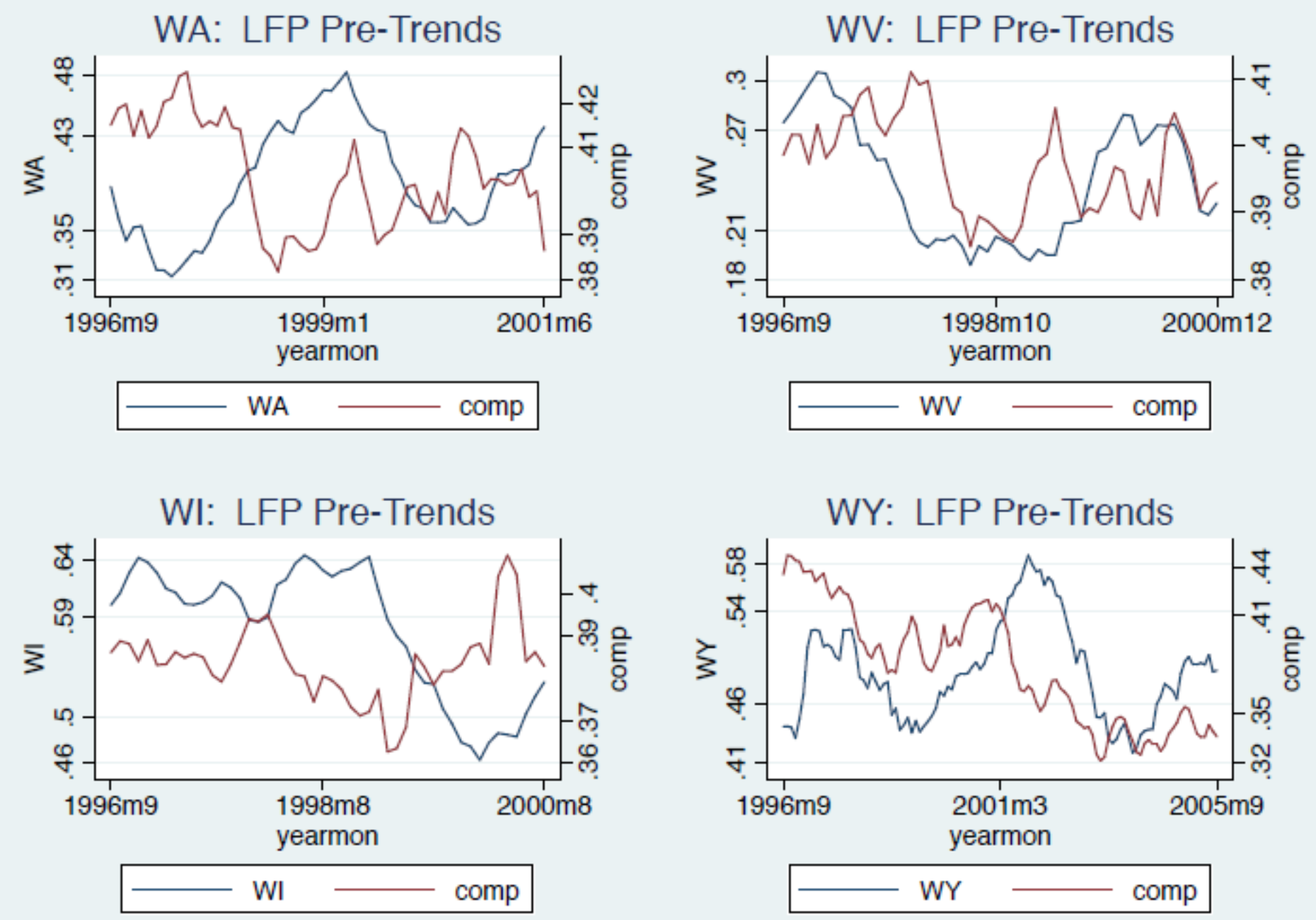